\title{
Aspectos da imersão em mídias sociais por MPEs de desenvolvimento de software: estudo de caso múltiplo
}

\author{
Jeanne Louize Emygdio ${ }^{I}$ \\ Adriana Prest Mattedi $i^{I I}$
}

\begin{abstract}
IUniversidade Federal de Itajubá, Itajubá, MG, Brasil. Doutoranda do PPGGOC/UFMG. Mestre em Desenvolvimento, Tecnologias e Sociedade pela Universidade Federal de Itajubá. Pesquisadora da Universidade Federal de Itajubá.

${ }^{I I}$ Doutora em Computação Aplicada pelo Instituto Nacional de Pesquisas Espaciais (2005). Professora adjunta IV da Universidade Federal de Itajubá.
\end{abstract}

http://dx.doi.org/10.1590/1981-5344/2580

O uso massivo de ferramentas tecnológicas colaborativas, como as mídias sociais, representa um desafio às organizações, frente à urgência de sua imersão no ciberespaço: contexto tecnológico digital global pósmoderno. Por imersão, compreende-se neste estudo, a entrada das empresas neste lócus, a fim de obterem acesso a informações estratégicas e desenvolverem maior capital relacional visando ampliar sua capacidade competitiva, seu desempenho colaborativo e vislumbrar maiores perspectivas de inovação. $O$ objetivo deste artigo é apresentar as práticas adotadas pelas MPES desenvolvedoras de software através da utilização de mídias sociais em seus trâmites interorganizacionais. $O$ estudo de caso múltiplo, natureza qualitativa e caráter descritivo, ocorreu em 21 empresas atuantes nas cidades de Itajubá (MG) e Santa Rita do Sapucaí (MG). Os resultados demonstram que, embora seja pouco significativa a compreensão sobre a importância da imersão, $58 \%$ das empresas participantes pretendem adotá-la sistematicamente. Há indícios de processos gradativos de imersão, sugerindo desenvolvimento progressivo de know-how para adaptação das estruturas organizacionais à essa tendência. 
Palavras-chave: Tecnologia da informação e comunicação. Mídias sociais. Redes sociais. Micro e pequenas empresas. Ferramentas sociais de colaboração.

\section{Aspects of social media adoption in technology-based small business: multiple case study}

The massive use of collaborative technological tools, such as social media, poses a challenge to organizations facing the urgency of their immersion in cyberspace: a postmodern global digital technological context. By immersion, this study includes the entry of companies at this locus in order to gain access to strategic information and to develop greater relational capital in order to increase its competitive capacity, its collaborative performance and to see greater perspectives of innovation. This article's purpose is to present adopted practices by Software Development SME through using social media in their interorganizational processes. The multiple case study, qualitative nature and descriptive character, occurred in 21 companies operating in the cities of Itajubá (MG) and Santa Rita do Sapucaí (MG). The results show that, although there is little understanding of the importance of immersion, 58\% of the participating companies intend to adopt it systematically. There are indications of gradual immersion processes, suggesting the progressive development of know-how to adapt organizational structures to this trend.

Keywords: Information and communication technology. Social media. Social networks. Micro and small business. Collaborative social tools.

Recebido em 18.06.2018 Aceito em 11.09.2018

\section{Introdução}

O advento da sociedade da informação contribuiu também para o reconhecimento das pequenas e médias empresas (PMEs) na economia mundial (DAFT, 2015; TAMBUNAN, 2008; BECK, 2013; RAMADANI et al., 2013). Segundo La Rovere (1999), até meados da década de 70, as PMEs tinham um papel pequeno no debate sobre o desenvolvimento econômico devido ao predomínio do paradigma da produção. A partir das transformações ocorridas na década de 80 , surge um novo modelo 
econômico, que permite a coexistência de diferentes sistemas de produção: a produção em escala em alguns setores e, em outros, 0 modelo de especialização flexível, baseada numa economia personificada, conforme o perfil do cliente e cujo principal capital está baseado em informação (DA SILVEIRA; BORESTEINS; FOGLIATO, 2001; SVENSSON; BARFORD, 2002; DAFT, 2015; STOJANOVA; SUZIC; ORCIK, 2012). As PMEs passaram a ter também um papel relevante, contribuindo para a geração de empregos, indução do crescimento regional, do movimento de downsizing, de terceirização e da inovação em busca de vantagens competitivas (IADB, 2002; OLIVEIRA; BERTUCCI, 2003; HOUSSEIN et al., 2011; TARUTÉ; GATAUTIS, 2014; LÉON; GUTIERREZ;FARRERO, 2017).

O cenário brasileiro das MPEs, tal como em diversos países, compreende simultaneamente, aspectos propícios à sua expansão, além de inúmeros desafios à sua subsistência e competitividade em ambientes globalizados e altamente competitivos (IADB, 2002; CRESSY, 2006; RIVERA, 2007; DOER, 2009). Estes desafios podem ser superados através de seu potencial inovador agregado às políticas de incentivo ao crédito, redução de alíquotas fiscais e incentivos legais para o controle da alta taxa de mortalidade empresarial nos primeiros anos de exercício, consequência do baixo nível de formação educacional e a pouca ou nenhuma experiência administrativa (CONFEDERAÇÃO NACIONAL DO COMÉRCIO CNC, 2000; LASTRES et al., 2002; CRAVO; GOURLEY; BECKER, 2012; TOMLINSON; FAI, 2013). Ressalta-se atualmente, a necessidade de reduzir a informalidade em grande número destes empreendimentos, sendo que essa abrangeu 46\% dos trabalhadores brasileiros em 2016 (ORGANIZAÇÃO INTERNACIONAL DO TRABALHO - OIT, 2018).

A adoção de TICs nos trâmites organizacionais oportuniza novas trajetórias de inovação e organização produtiva a partir da renovação do processo de destruição criadora o que pode repercutir positivamente no potencial competitivo das empresas (SCHUMPETER, 1997; RADAS; BOZIC, 2009; LAUDON; LAUDON, 2010; TIGRE, 2011). Tal afirmação permite a percepção dos impactos da adoção destas tecnologias na ampliação de mercados econômicos; no rompimento de barreiras sociais, políticas e culturais; na formalização de alianças empresariais para produção de conhecimentos técnicos e científicos e, de forma mais ampla, no estabelecimento de redes de relacionamentos nacionais e internacionais capazes de contribuir significativamente para a prosperidade das empresas e de seu entorno (BUGHIN; BYERS; CHUI, 2011; JARRACHI; SAWYER, 2013).

Assim, a economia e a sociedade se auto-organizam de forma virtual no ciberespaço, através da estruturação em redes de colaboração, criando arranjos inovadores (MELLO; FONSECA; VIEIRA, 2012) e provocando uma ruptura do paradigma anterior (CASTELLS, 1999; LEVY, 1998; 2001). As tecnologias, embora concebidas segundo estratégias contextualizadas, em diferentes condições e projetos de desenvolvimento social nos países onde se originaram, vêm transformando as estruturas e as práticas produtivas, comerciais, consumistas, cooperativas e competitivas entre os agentes, alterando a própria cadeia de geração de 
valor e da sociedade (LATOUR, 2010; ARORA; ARORA; PALVIA, 2014; LAROSILIERE; CARTER; MESKE, 2017).

Segundo Lévy (2001), para que estes novos cenários de territórios virtualizados sejam utilizados de forma sinérgica, torna-se necessário o desenvolvimento de competências para compreensão e utilização de seus recursos e mecanismos. Assim, as organizações modificam sua estrutura funcional interna, a qualificação dos recursos humanos bem como a forma de relacionamento com fornecedores, clientes, parceiros e órgãos públicos com vistas a alcançar capacitação técnica e experimentação que oportunizem a transformação da informação (altamente transferível, se não proprietária), em conhecimentos tácitos, e estes, em ferramenta útil à produção (TIGRE, 2011; ARORA; ARORA; PALVIA, 2014). Sob estas condições, as empresas passam a usufruir de uma via digital positiva e significativa para a divulgação e escoamento de produtos e serviços inovadores que podem ser rapidamente conhecidos e adquiridos por outras empresas participantes das redes sociais.

O objetivo deste artigo é apresentar as práticas adotadas pelas MPEs desenvolvedoras de software através da utilização de mídias sociais em seus trâmites interorganizacionais. Tais práticas, observadas sob o ponto de vista dos empresários, permitem uma avaliação sobre o grau de maturidade empresarial quanto à percepção de sua viabilidade e valor.

O artigo está dividido em cinco seções onde são apresentados: as micro e pequenas empresas no Brasil; as TICs, as mídias sociais e redes sociais virtuais; a metodologia estabelecida para a pesquisa; os resultados obtidos e as conclusões.

\section{As micro e pequenas empresas no Brasil}

Originárias da época do Brasil Colônia quando se caracterizavam por atividades manufatureiras, comerciais, agrícolas, de prestação de serviços e transportes (SOUZA; MACHADO; OLIVEIRA, 2007), as MPEs brasileiras desenvolveram-se ao longo do tempo e se tornaram importantes na elaboração de políticas públicas de estímulo ao desenvolvimento produtivo tendo em vista os impactos econômicos e sociais gerados em seu entorno ao longo da história (MATOS; ARROIO, 2011).

A constituição legal das MPEs no Brasil iniciou-se no ano de 1984, com a aprovação do Estatuto da Microempresa, que "normas para tratamento diferenciado, simplificado e favorecido às MPEs nos campos administrativos, tributários, previdenciários, trabalhistas, creditícios e de desenvolvimento empresarial" (BRASIL, 1984, p.1). Em 1988, a Constituição Federal distinguiu as Microempresas das Empresas de Pequeno Porte e também estabeleceu, no artigo 179, tratamento jurídico diferenciado às MPEs com vistas à simplificação ou mesmo eliminação de obrigações nos mesmos campos previstos no Estatuto da Microempresa (BRASIL, 1988). Nos anos seguintes, o Brasil avançou em termos de Legislações e instrumentos regulatórios visando acolher o maior número de empresas, setores e microempreendedores; ampliar o âmbito de aplicação das leis, inicialmente circunscrito à Federação, para Estados e 
Municípios; gerar mecanismos tributários diferenciados para as MPEs como o Simples Federal e o Nacional, e a autorização para parcelamento de dívidas de microempreendedores neles inscritos, visando simplificar as obrigações financeiras do microempreendedor, reduzir a taxa de informalidade e oferecer estímulos à exportação (BRASIL, 1999; 2006; SEBRAE, 2012, 2015a).

Em termos de classificação das MPEs, não existe um consenso e as definições geralmente "utilizam critérios qualitativos e quantitativos, recaindo em aspectos de pessoal ocupado ou de nível de faturamento" (GARÓFALO, 2009, p. 2808). No Brasil, as principais classificações utilizadas para enquadramento das MPEs são: (i) por faturamento adotado pela Lei Geral das Micro e Pequenas Empresas (BRASIL, 2006, p.4) e pelo Serviço Brasileiro de Apoio às Micro e Pequenas Empresas (SEBRAE) em concordância a Lei Complementar no 123, de 2006, porém com distinções para o Microempreendedor Individual (MEI) e para o Pequeno Produtor Rural para o qual adota também o número de módulos fiscais (SEBRAE, 2015a); (ii) por Receita Operacional Bruta - adotado pelo Banco Nacional de Desenvolvimento (BNDES, 2010; 2011); e (iii) por número de pessoal ocupado: adotado pelo SEBRAE para efeito de estudos (SEBRAE, 2015b). Há distinção por setores da indústria e construção civil e do comércio e serviços. A variação das conceituações é apresentada na Tabela 1.

Tabela 1 - Classificação do porte das empresas segundo a LC 123/2006, BNDES e Sebrae

\begin{tabular}{|c|c|c|c|c|c|}
\hline \multirow{3}{*}{$\begin{array}{l}\text { Tamanho das } \\
\text { empresas }\end{array}$} & \multirow{3}{*}{$\begin{array}{c}\mathbf{L C ~ N}^{\mathbf{0}} \mathbf{1 2 3 / 2 0 0 6} \\
\text { (Faturamento } \\
\text { Bruto anual) }\end{array}$} & \multicolumn{3}{|c|}{ SEBRAE } & \multirow{3}{*}{$\begin{array}{c}\text { BNDES } \\
\text { (Receita Operacional } \\
\text { Bruta Anual) }\end{array}$} \\
\hline & & \multirow{2}{*}{$\begin{array}{c}\text { (Faturamento Bruto } \\
\text { Anual / Módulos Fiscais) }\end{array}$} & \multicolumn{2}{|c|}{ (Número de pessoal ocupado) } & \\
\hline & & & $\begin{array}{c}\text { Indústria e } \\
\text { construção civil }\end{array}$ & $\begin{array}{l}\text { Comércio e } \\
\text { serviços }\end{array}$ & \\
\hline $\begin{array}{l}\text { Microem- } \\
\text { preendedor } \\
\text { individual }\end{array}$ & \multirow{2}{*}{$\begin{array}{l}\text { Até } \mathrm{R} \$ \\
360.000,00\end{array}$} & $\begin{array}{c}\text { Até } \\
\mathrm{R} \$ 60.000,00\end{array}$ & 1 & 1 & --- \\
\hline Micro-empresa & & $\begin{array}{c}\text { Até } \\
\mathrm{R} \$ 360.000,00\end{array}$ & Até 19 & Até 9 & $\begin{array}{c}\text { Até } \\
\mathrm{R} \$ 2,4 \text { milhões }\end{array}$ \\
\hline $\begin{array}{l}\text { Pequena } \\
\text { empresa }\end{array}$ & \multicolumn{2}{|c|}{$\begin{array}{c}\text { De } \\
\mathrm{R} \$ 360.000,01 \text { a } \mathrm{R} \$ 3.600 .000,00 \text { inclusive }\end{array}$} & $\begin{array}{c}\text { Entre } \\
20 \text { e } 99\end{array}$ & $\begin{array}{l}\text { Entre } \\
10 \text { e } 49\end{array}$ & $\begin{array}{c}\text { De } \mathrm{R} \$ 2,4 \text { milhões a } \\
\mathrm{R} \$ 16 \text { milhões } \\
\text { inclusive }\end{array}$ \\
\hline $\begin{array}{c}\text { Pequeno } \\
\text { produtor rural }\end{array}$ & --- & $\begin{array}{l}\text { Propriedade com até } \\
\text { quatro módulos fiscais } \\
\text { ou faturamento } \\
\text { anual de até } \\
\text { R\$ 3,6 milhões }\end{array}$ & --- & --- & \\
\hline Média empresa & --- & --- & $\begin{array}{c}\text { Entre } \\
100 \text { e } 499\end{array}$ & $\begin{array}{c}\text { Entre } \\
50 \text { e } 99\end{array}$ & $\begin{array}{c}\text { De R\$ } 16 \text { milhões a } \\
\mathrm{R} \$ 90 \text { milhões } \\
\text { inclusive }\end{array}$ \\
\hline $\begin{array}{l}\text { Média-grande } \\
\text { empresa }\end{array}$ & --- & --- & --- & --- & $\begin{array}{c}\text { De R \$ } 90 \text { milhões a } \\
\text { R \$ } 300 \text { milhões } \\
\text { inclusive }\end{array}$ \\
\hline $\begin{array}{l}\text { Grande } \\
\text { empresa }\end{array}$ & --- & --- & Acima de 499 & Acima de 50 & $\begin{array}{c}\text { Acima de } \\
\mathrm{R} \$ 300 \text { milhões }\end{array}$ \\
\hline
\end{tabular}


Fonte: Adaptado de BRASIL (2006); BNDES (2010; 2011); SEBRAE (2015a; 2015b).

Tabela 2 - Temáticas

\begin{tabular}{lcc}
\hline \multicolumn{1}{c}{ Temática } & n* & \% \\
\hline \hline Relação familiar & 63 & 32 \\
Relação dos adolescentes com a escola & 27 & 14 \\
Influência do grupo na adolescência & 26 & 13 \\
Drogas & 24 & 12 \\
Violência & 24 & 12 \\
Bulimia e anorexia & 18 & 9 \\
Puberdade & 5 & 3 \\
Acne & 5 & 3 \\
Gravidez na adolescência & 5 & 3 \\
\hline Total & $\mathbf{1 9 7}$ & $\mathbf{1 0 0}$ \\
\hline
\end{tabular}

Fonte: Dados da pesquisa.

Observa-se que, nas três conceituações, há base para classificação por valores monetários do Faturamento Bruto anual e da Receita Operacional Bruta anual das empresas. $\mathrm{Na}$ segunda conceituação, encontra-se ainda uma classificação por número de pessoal ocupado que é utilizada para efeito de estudos e análises. Utilizando-se a terceira conceituação, observa-se uma caracterização das empresas por maior número de categorias, sendo elas: Microempresa, Pequena Empresa, Média Empresa, Média-grande empresa e Grande empresa. Nesta pesquisa utilizou-se a classificação por número de pessoal ocupado pelo fato de que o valor de faturamento bruto das empresas constitui-se em uma informação estratégica de difícil acesso.

As MPEs vêm se destacando de maneira relevante no funcionamento da economia do país em virtude de sua capacidade de absorção de mãode-obra (principalmente aquela que inicia seu próprio negócio empreendedores individuais), da geração de renda, do número de estabelecimentos e do potencial de abertura de novos negócios. No ano de 2012, estatísticas do Instituto Brasileiro de Geografia e Estatística (IBGE) apontaram que as MPEs representavam $20 \%$ do Produto Interno Bruto (PIB) brasileiro, sendo responsáveis por $60 \%$ dos 94 milhões de empregos no país, constituindo $99 \%$ dos seis milhões de estabelecimentos formais nacionais. A maior parte dos negócios localizava-se na região Sudeste (com quase três milhões de empresas) e o setor preferencial era 0 comércio, seguido de serviços, indústria e construção civil (BRASIL, 2012). Entretanto, a participação das MPEs no PIB brasileiro comparada à participação das MPEs no PIB em outros países mais desenvolvidos (como a Argentina, onde contribuem com $60 \%$, o Peru com $42 \%$, os EUA e Itália com $50 \%$ ) é considerada pequena (CONFEDERAÇÃO NACIONAL DO COMÉRCIO - TVCNC, 2015).

Segundo o Sebrae (2013), no que diz respeito à evolução das MPEs no Brasil impulsionada pela expansão da renda e do crédito no período entre 2002 e 2012, houve um crescimento médio do número de MPEs de $2,7 \%$ a.a., ou seja, aproximadamente 1,5 milhão de novos 
estabelecimentos foram criados; (ii) houve um crescimento médio anual do número de empregados nas MPEs de 5,4\% a.a. Em todo o período houve a criação de 6,6 milhões de empregos com carteira assinada; (iii) 0 bom desempenho das MPEs neste período confirmou a sua importância para a economia: de cada $\mathrm{R} \$ 100$ pagos aos trabalhadores no setor privado não agrícola, cerca de $\mathrm{R} \$ 40$, em média, foram pagos por MPEs; (iv) nas análises setoriais observou-se que a indústria apresentou ligeira queda na sua participação relativa, saindo de $11 \%$ do total das MPEs em 2002 para 10,8\% em 2012 (683 mil MPEs). No sentido inverso, a participação do setor da construção cresceu de 3,8\% do total de MPEs em 2002 para 5,1\% em 2012 (325 mil estabelecimentos em 2012); e ( $v$ ) no ano de 2012, a distribuição dos estabelecimentos com e sem empregados por setor apresentou destaque para os microempresários individuais dos setores de comércio e serviços.

Embora as pesquisas apontem para o aumento quantitativo de MPEs no país como sinalizadores representativos da importância do segmento para o crescimento econômico nacional (CRAVO; GOURLEY; BECKER, 2012), outros fatores também concorrem para este mesmo fim, como por exemplo, a concentração de capital humano empreendedor nas MPEs que amplia a concorrência no mercado a partir das inovações que introduz (BARROS; PEREIRA, 2008), e o capital relacional desenvolvido estrategicamente por estas empresas com vistas à superação de restrições técnicas e financeiras, alcance de status e legitimidade, geração de benefícios econômicos e simplificação da gestão da dependência de recursos (cooperativas, por exemplo), o que fortalece estas empresas aumentando sua capacidade competitiva e de sobrevivência (ALMEIDA; BRIONES; FERNANDES, 2011; WEGNER; MISOCSKY, 2010; PASCHEN, 2017).

Segundo Degen (2008), o impacto do empreendedorismo no crescimento econômico de um país está diretamente relacionado à motivação que o próprio país oferece à prática, seja através de melhorias na educação, no treinamento da população, no aumento do número e da qualidade dos centros de pesquisa e de tecnologia, de maior disponibilidade de capital de risco, da profundidade do mercado, da existência de uma infraestrutura adequada ou na elaboração de legislação pertinente. Empresários mais bem preparados, ou, empreendedores motivados por oportunidade, desenvolvem maior volume de negócios baseados em inovações e novas tecnologias, o que resulta em maior geração de emprego e renda. O contrário também se verifica e, nestes casos, os empresários são identificados como empresários motivados pela necessidade, não apresentando habilidades, motivação ou oportunidades para serem empreendedores. Na China, 60\% dos negócios são motivados por oportunidade, na Índia, 65\%, tais índices são explicados pelo excelente nível das suas universidades e pelas oportunidades geradas por economias de desenvolvimento acelerado como as de ambos os países (GLOBAL ENTREPRENEURSHIP MONITOR - GEM, 2015).

A habilidade e a capacidade criativa dos micro e pequenos empreendedores os tornam capazes de competir com eficiência em 
mercados acirrados, tanto regionais quanto globais (MORIONES; LÓPEZ, 2007; ALAM; NOOR, 2009; TARUTÊ; GATAUTIS, 2014), ainda que as grandes empresas, em especial devido a seu poder financeiro, obtenham maior acesso às tecnologias mais avançadas saindo à frente na corrida competitiva (ASHRAFI; MURTAZA, 2008). A habilidade em perceber, monitorar e utilizar as informações inseridas no ciberespaço, por exemplo, poderá se constituir em instrumento útil para a sobrevivência e 0 desenvolvimento de uma empresa (KAPLAN; HAENLEIN, 2010; VALE; GUIMARAES, 2010, PALACIOS-MARQUÊS; MERIGÓ; SOTO-ACOSTA, 2015; FIRE; PUZIS, 2016; LEENDERS; DOLFSMA, 2016) considerando-se as possibilidades de elaboração de estratégias de inovação tendo por base a aquisição de conhecimentos provenientes das ações de imersão neste espaço, conforme será apresentado na próxima seção.

\section{As TICs, as mídias sociais e as redes sociais virtuais}

Apesar da abrangência de conceitos sobre TICs, conforme apontado por Zuppo (2012), para este estudo elas representam todos os recursos de informática utilizados para tratamento de dados, produção de informação e geração de conhecimentos (REZENDE, 2007) que permitam a tomada de decisões eficazes, eficientes e efetivas. Abrangem recursos de hardware, software, tecnologias de gestão de dados, sistemas de telecomunicações, serviços de tecnologia, sistemas de informação e redes de computadores (CASTELLS, 1999; LAUDON; LAUDON, 2010; CAIÇARA JUNIOR, 2012).

No contexto econômico e social atual, as TICs se configuram como essenciais para o acesso à informação e à Sociedade do Conhecimento. Elas imprimem nova dinâmica econômica, social e cultural no cotidiano de indivíduos e empresas; transformando hábitos, formas de viver e produzir, com ênfase na otimização do tempo e da produtividade do trabalho (ASSOCIAÇÃO PARA PROMOÇÃO DA EXCELÊNCIA DO SOFTWARE BRASILEIRO - SOFTEX, 2013). Tais transformações demandam constante processo de atualização, para que as pessoas possam enfrentar os desafios pós-modernos (IBGE, 2011).

Em empresas, as TICs permeiam todas as áreas funcionais, desde a automação de postos de trabalho, em escritórios e postos de atendimento a clientes internos e externos, até ao apoio a tomada de decisões da alta gerência (OLIVEIRA, 2007). Isto requer a existência de processos para alinhar as TICs aos negócios e estratégias da empresa, bem como de habilidades empresariais para sua gestão (HENDERSON; VENKATRAMAN, 1990). Assim, para que uma empresa possa se tornar competitiva a partir do uso de TICs, é pertinente a articulação adequada de suas três dimensões: humana, organizacional e tecnológica no entorno do ferramental tecnológico escolhido e dos objetivos claros que se pretende alcançar.

Segundo Laudon e Laudon (2010), a utilização de TICs pelas empresas visa atingir seis objetivos organizacionais, a saber: excelência operacional a partir de mudanças nos fluxos de processos e nas práticas 
de negócios; descoberta/desenvolvimento de novos produtos, serviços e modelos de negócios a partir da pesquisa contínua no entorno de novas TICs, capacitação de mão-de-obra e utilização efetiva dos recursos; relacionamento mais estreito com clientes e fornecedores a partir de ferramentas de coleta e análise de dados dos clientes; melhoria na tomada de decisão tendo por base sistemas de apoio à decisão e de business intelligence; ampliação de vantagem competitiva a partir do alcance dos objetivos anteriormente relacionados; garantia de sobrevivência a partir da (re)modelagem do negócio em torno essencialmente de sistemas de informação e outros recursos de TICs. E os benefícios que a adoção de TICs proporciona às empresas, tanto pelo advento dos computadores pessoais e das tecnologias móveis, quanto pela baixa do custo de aquisição destes recursos, podem ser percebidos através do aumento da produtividade e performance da companhia; da possibilidade de realização de negócios em rede ou em cadeias de suprimentos; incremento do valor agregado de produtos e serviços; do acesso a novos mercados; da criação de novos produtos/serviços; da utilização de novos canais de negócios; da reação rápida à novos negócios de empresas competidoras; do maior valor da empresa no mercado; de maior rentabilidade e/ou redução de custos; de maior eficiência nos processos; e satisfação dos clientes (MORIONES; LÓPEZ, 2007; ANTLOVÁ, 2009; NGUYEN; NEWBY; MACAULAY, 2015; KHAN; AL-YASIRI, 2016; CHOSHIN; GHAFFARI, 2017; BOHN; KUNDISCH, 2018).

Contudo, escolhas tecnológicas inadequadas podem resultar em gastos excessivos, subutilização ou perda de competitividade (IBGE, 2011). Tal afirmação encontra respaldo em Mattos e Guimarães (2005) ao sinalizarem que a relação entre tecnologia e vantagem competitiva é por vezes mal compreendida, pois uma escolha tecnológica pode não ser economicamente justificável, ou não estar ajustada ao perfil de prioridades competitivas desejadas, ou pouco agregar às competências centrais da empresa. Ainda, cabe ressaltar que as TICs continuam sendo aplicadas como recurso de alcance e manutenção da eficiência operacional nas organizações, sem que seu potencial seja plenamente aproveitado "como recurso de apoio em atividades de planejamento estratégico e de inteligência competitiva" (BARBOSA; NASSIF, 2012, p.114).

No universo representado pelas TICs, optou-se nesta pesquisa pela investigação das mídias sociais em função de seu longo alcance (acesso global), alta disponibilidade (conectividade) e baixo custo para imersão. Características essas que possibilitam a observação direta do comportamento de múltiplos atores no ciberespaço, das inter-relações que constroem e se multiplicam em segundos, seus interesses e demandas. Tal cenário configura-se para os empreendedores como altamente profícuo à definição de estratégias competitivas e inovadoras (ALBERGHINI; CRICELLI; GRIMALDI, 2014; DIJKMANS; KERKHOF; BEUKEBOOM, 2015; SINGARAJU et al., 2016).

O estudo das mídias sociais requer a distinção entre dois termos amplamente utilizados por diversos pesquisadores, muito embora ainda não haja consenso sobre suas definições: mídias sociais e redes sociais. 
Segundo Bradley e McDonald (2013, p.26), por mídia social compreendese um "ambiente online criado com o propósito da colaboração em massa". As redes sociais, ou comunidades são os agrupamentos de pessoas reunidas por um propósito comum, como por exemplo, os grupos do Facebook ou os grupos de stakeholders de uma organização. Os propósitos definem uma comunidade e levam seus participantes a compartilharem seus conhecimentos, ideias e experiências. Sem um propósito, as pessoas não constroem as redes de relacionamento nas mídias sociais, passando a utilizá-las apenas para exposição pessoal. Embora a palavra "mídia" refira-se a qualquer instrumento, meio ou veículo de comunicação social, como o jornal, o rádio, a televisão ou a imprensa de modo geral, que oferecem oportunidades mínimas de interação, estas também se encontram em processo de convergência para integração com as mídias sociais (SOARES; BORGES, 2008). A Figura 1 representa os conceitos apresentados.

Figura 1 - Mídias Tradicionais x Mídias Digitais



Fonte: Elaborado pelas autoras.

Segundo Marteleto (2001), redes sociais abrangem grupos autônomos, que compartilham ideias, valores e interesses. Estes grupos, interligados por meio de uma internet dinâmica e globalizada,passaram a ser definidos como instrumentos organizacionais, com capacidade de adentrar nos métodos de interação existentes entre pessoas e, consequentemente, transformá-los. Segundo Lévy (1996), tais redes, ou comunidades virtuais, representam a virtualização dos agrupamentos sociais. Para Recuero (2011), as redes sociais têm substituído as mídias tradicionais (por exemplo, rádio e televisão) na circulação de informações e propiciam que estas possam ser filtradas, debatidas, discutidas e repassadas, gerando assim, novas formas de organização social, baseadas em interesses da coletividade. Para a autora, o estudo das redes sociais na internet foca o problema de como as estruturas sociais surgem, de que tipo são, como são compostas através da comunicação mediada pelo computador e como essas interações mediadas são capazes de gerar fluxos de informações e trocas sociais que impactam essas estruturas.

As mídias sociais instrumentalizam a produção e o intercâmbio de conteúdos, gerados, em grande parte, pelos próprios usuários, prática denominada de User Generated Content (UGC), e que abarca os diversos modos que as pessoas podem utilizá-las (KAPLAN; HENLEIN, 2010), anteriormente limitados quanto à interação nas mídias tradicionais (SOARES; BORGES, 2008). São aplicações de internet fundamentadas nos 
conceitos da Web $2.0^{1}$ e Web 3.0 que compõem um amplo ecossistema de serviços online, percebido e estruturado por vários pesquisadores sob ângulos diferentes, tais como: por esferas de influência para a área de marketing integrando mídias tradicionais e digitais (ABREU, BALDANZA; SETTE, 2008; HANNA; ROHM; CRITTENDEN, 2011); por níveis de stakeholders, com ênfase na coleta de dados sociais para integração com softwares de Customer Relationship Management (CRM - Gestão de Relacionamento com Clientes) (JORDAN EDMISTON GROUP INC. (JEGI) AND INTERACTIVE ADVERTISING BUREAU (IAB) - JEGI/IAB, 2012); por permitir de forma não exclusiva a realização das atividades de publicação, compartilhamento, discussão e socialização (networking) (CAVAZZA, 2015); por tipo de mídias sociais, abrangendo os blogs, microblogs, comunidades de conteúdo, redes sociais, computação em nuvem, feedback social, fóruns de discussão, ferramentas de ideias, fóruns de respostas e mundos virtuais (KAPLAN; HAENLEIN, 2010; BRADLEY; MCDONALD, 2013; RAZMERITA; KIRCHNER; NABETH, 2014; NGAI et al., 2015). Vale ressaltar que a estruturação de ecossistemas internos nas organizações é incentivada por Bradley e McDonald (2013), com vistas à integração de seu ambiente interno de colaboração, aos ambientes externos evitando-se a criação de ilhas sociais que limitam seu valor para a organização e provocam problemas de duplicação e segurança dos dados, autoridade, duplicação do esforço, processamento manual e fluxos de trabalho deslocados, resultando em queda da participação dos usuários na construção de uma cultura social na empresa.

A utilização de mídias sociais nas organizações pode contribuir para a gestão do conhecimento coletivo e pessoal a partir do uso das redes sociais, wikis, blogs, microblogs e comunidades de conteúdo de forma sinérgica (RAZMERITA; KIRCHNER; NABETH, 2014). Para isso, Mello, Fonseca e Vieira (2012) apontam que há uma relação entre a percepção de oportunidades e a forma como gestores de empresas de base tecnológica geram sentido de suas atividades em seu cotidiano de negócios (sensemaking). No entanto, o alcance de transformações organizacionais impactantes, a partir do uso de ferramentas de colaboração, depende de uma evolução significativa nos comportamentos individuais e organizacionais frente à informação e ao conhecimento, pois, não basta as empresas operacionalizarem as ferramentas tecnológicas, é necessário "desenvolverem competências para utilizar estrategicamente a informação e o conhecimento, pois este é o diferencial competitivo do ambiente de negócios contemporâneo" (BARBOSA; SEPÚLVEDA; COSTA, 2009, p.23; SINGARAJU et al., 2016; SANTOS; SAMPAIO, 2016; MOZASMORAL et al., 2016).

\footnotetext{
${ }^{1}$ Segundo Kaplan e Haenlein (2010) o conceito foi utilizado pela primeira vez em 2004 para descrever um novo modo de utilização da internet por desenvolvedores de software e usuários finais, caracterizado pela construção e modificação contínua, participativa e colaborativa de conteúdos e aplicações por todos os usuários. Segundo Castells (1999), Web 2.0 e Web 3.0 "representam o aglomerado de tecnologias, dispositivos e aplicações que dão suporte à proliferação de espaços sociais na internet graças ao aumento da capacidade de largura de banda, à difusão de softwares de código aberto e à melhoria da parte gráfica e de interface dos computadores, inclusive a interação com avatares em espaços virtuais tridimensionais".
} 
A título de ilustração, uma pesquisa realizada pela Deloitte Touche Tohmatsu Limited (DELLOITE, 2010) com 302 empresas atuantes em diversos setores da economia sendo $50 \%$ das respondentes, de pequeno porte revelou que: a) $70 \%$ das empresas utilizam ou monitoram as atividades nas mídias sociais; b) destas, o maior número de empresas encontra-se nos setores de serviços, varejo, bens de consumo e transporte e tecnologia, mídia e telecomunicações, respectivamente; c) as ferramentas mais utilizadas são as redes sociais, os microblogs e os blogs e d) as iniciativas mais exploradas por estas empresas nas mídias e redes sociais virtuais são as ações de marketing e de divulgação de produtos ou serviços; o monitoramento da marca ou mercado e a venda ou captura de oportunidades.

No entanto, um dos desafios para a adoção de TICs reside na compreensão exata do valor de uma tecnologia para o negócio de uma empresa uma vez que os impactos de adoção podem gerar consequências tanto positivas quanto negativas (NAGLE; POPE, 2013). A ausência de consenso sobre o que caracteriza uma métrica ideal para se medir esse valor aumenta o desafio tendo em vista a emergência da tecnologia em nossa sociedade. Tais obstáculos aplicam-se também à seleção das mídias sociais a serem adotadas que, para estes autores devem ser escolhidas a partir de quatro critérios, a saber: a) Inteligência: estágio de préplanejamento onde se percebe o valor que a mídia social terá para os negócios; b) Design: a partir da flexibilidade das mídias sociais a empresa analisa as opções e estratégias organizacionais que deseja implementar; c) Escolha: a partir das análises anteriores, a empresa deverá escolher dentre as mídias aquela(s) que mais se aproxime $(\mathrm{m})$ das suas necessidades; d) Revisão: a empresa revisa as perspectivas de sucesso ou de falha das aplicações tendo por base as premissas estabelecidas na fase de inteligência.

Kaplan e Haenlein (2010) elencam cinco cuidados importantes para utilização adequada das mídias sociais: a) conhecer as mídias sociais disponíveis e escolher cuidadosamente; b) decidir por desenvolver mídia própria adequada ao negócio ou adquirir ferramentas específicas; c) ao escolher várias mídias para utilização, certificar-se de que elas possam trabalhar alinhadas, tanto em termos de funcionalidades quanto de procedimentos; d) planejar a integração das mídias tradicionais com as sociais; e) garantir o acesso a todos os funcionários com vistas a criar uma empresa social.

Outro item importante no que tange à adoção das mídias sociais repousa sobre a definição de métricas de monitoramento que traduzam para os empresários os resultados da imersão, sendo possível a geração de informações vitais para todos os departamentos da empresa, quando bem estruturadas (MONTEIRO; AZARITE, 2012). Sua definição é complexa em virtude da análise recair sobre comportamento dinâmico das pessoas em torno dos canais empresariais. Há iniciativas no sentido de se definir frameworks de apoio a estas atividades, podendo-se citar o trabalho de Peters et al. (2013) que, embasando-se em inúmeras pesquisas realizadas no período de 2010 a 2012, propôs um complexo framework que avalia: 
a) as motivações dos atores nas mídias sociais tendo por base seu valor intelectual, social e cultural; b) o conteúdo, compreendendo a qualidade, o teor e o volume; c) a estrutura de rede, compreendendo número de conexões e segmentação; e d) as regras e interações sociais.

Para Bolsinger e Staff (2015), as métricas podem ser classificadas em: a) Quantitativas: Alcance (número de seguidores, fans, usuários), Engajamento (número de compartilhamentos, comentários e retweets), Timing (período de maior atividade da comunidade em torno da mídia social), Taxa de retorno (usuários que retornam ao site - revisitam) e b) Qualitativas: Influência, Sentimento (Tom e teor de conversações em torno de um tópico ou item), Tendências (tópicos e contexto das conversas sobre a empresa, concorrentes e nichos).

A IAB (2009) utiliza as seguintes métricas para mídias sociais: Visitante único (que acessou o site da mídia social apenas uma vez), Custo por visitante único (total do custo da hospedagem ou da aplicação dividida pelo número de visitantes únicos), Número de visitantes, Número de revisitas, Tempo gasto pelo usuário na mídia, Número de vídeos instalados (ou postados na mídia social), Ações relevantes realizadas pelo usuário.

Outra forma de utilização de métricas foi proposta por Bonsón e Flores (2011), que analisaram as ações em mídias sociais realizadas por 46 instituições financeiras, sendo 23 Norte Americanas e 23 Europeias, utilizando métricas que classificavam as ações destas entidades no entorno de seus canais sociais em dois níveis: a) existência passiva ou conversação: que consiste em detectar o nome das entidades que postam (ou replicam, retwitam, compartilham, etc.) os conteúdos relacionados às instituições financeiras (sem, no entanto, terem vínculos diretos com as mesmas), em comunidades online (vídeos do Youtube, grupos e páginas do Facebook, grupos do LinkedIn, etc.), e que são listados em máquinas de busca utilizados pelas instituições financeiras; b) existência ativa ou presença direta: que consiste em localizar as páginas e grupos oficiais do Facebook, grupos de empregados no LinkedIn, canais do Twitter mantidos pela entidade e vários outros critérios relacionados. A análise final permitiu estabelecer um cenário comparativo de imersão em mídias pelos dois grupos de instituições nos seguintes aspectos: existência de canais oficiais por mídia social; existência de grupos oficiais por mídia social; número de membros nos grupos oficiais por mídia social; número de seguidores, páginas oficiais, fanpages, inscrições e conversações por mídia social; período de atividade por mídia social.

A partir do contexto apresentado, compreende-se a possibilidade de estudo e análise da relação das MPEs em seu ecossistema interorganizacional a partir da imersão nas mídias sociais e redes sociais virtuais.

\section{Condução da pesquisa}

Para a definição do escopo do objeto de estudo foram escolhidas as cidades de Itajubá e Santa Rita do Sapucaí, ambas situadas no sul de 
Minas Gerais. Tal escolha justifica-se pela importância de ambas enquanto pertencentes a pólos tecnológicos; pela presença de duas grandes universidades, a Universidade Federal de Itajubá (UNIFEI) e o Instituto Nacional de Telecomunicações (INATEL), ambas fortes incentivadoras do surgimento de novas MPEs a partir de suas Incubadoras de Empresas; da presença do Arranjo Produtivo Local de Santa Rita do Sapucaí; pela irradiação tecnológica proporcionada por estas cidades e pelo número de empresas atuantes nesta região. Dentre as empresas de base tecnológica, foram selecionadas para compor o espaço amostral definitivo desta pesquisa aquelas que possuem como atividade principal ou secundária, os serviços de tecnologia da informação e comunicação, isto é, cuja receita bruta resulte, no todo ou em parte, das seguintes atividades (Classificação Nacional de Atividades Econômicas - CNAE 2.0): a) 6201-5 Desenvolvimento de programas de computador sob encomenda; b) 62023 - Desenvolvimento e licenciamento de programas de computador customizáveis; c) 6203-1 - Desenvolvimento e licenciamento de programas de computador não-customizáveis. A escolha dos referidos CNAEs justifica-se pelas orientações encontradas nas diretrizes internacionais para estudos sobre atividades inovadoras na indústria, apreendidas da Organização para a Cooperação e o Desenvolvimento Econômico (OCDE, 2004), que indica o setor como área provável para pesquisas sobre inovação, desempenhando papel importante na geração de conhecimento, além do fato destes segmentos terem se destacado como inovadores em produto ou processo no Brasil no período de 2009 a 2011 (IBGE, 2013). No primeiro semestre de 2015, o setor de serviços se destacou como o maior em número de MPEs formalizadas, com 45,2\% do total (CNC, 2015).

Para realização de uma análise preliminar dos objetos de pesquisa inicialmente foram levantados os seguintes dados empresariais: Cadastro Nacional de Pessoa Jurídica (CNPJ), número de empregados, receita anual, área de atuação e os parceiros comerciais. Em função do nível de confidencialidade dos dados sobre faturamento, a seleção final das empresas baseou-se no número de empregados (SEBRAE, 2015b). O espaço amostral inicial foi composto por 30 microempresas de base tecnológica, 15 localizadas na cidade de Itajubá e 15 na cidade de Santa Rita do Sapucaí, distribuídas entre os elementos concentradores apresentados no Quadro 1.

Quadro 1 - Espaço amostral

\begin{tabular}{c|l|c|c}
\hline \multirow{2}{*}{ Cidade } & \multicolumn{1}{|c|}{ Elemento concentrador } & Tipo de empresa & Qtd. \\
\hline \hline \multirow{2}{*}{$\begin{array}{c}\text { Santa Rita } \\
\text { do Sapucaí }\end{array}$} & $\begin{array}{l}\text { Programa Municipal de Incubação Avançada de Empresas de Base } \\
\text { Tecnológica - PROINTEC }\end{array}$ & Residentes & 6 \\
\cline { 2 - 2 } & Núcleo de Empreendedorismo do INATEL - NEMP & & 3 \\
\cline { 2 - 3 } & Incubadora de Base Tecnológica da FAI - INTEF & & 3 \\
\cline { 2 - 4 } & $\begin{array}{l}\text { Sindicato das Indústrias de Aparelhos Elétricos, Eletrônicos e Similares do } \\
\text { Vale da Eletrônica }\end{array}$ & \multirow{2}{*}{ Associadas } & 3 \\
\hline
\end{tabular}




\begin{tabular}{c|l|c|c}
\hline \multirow{2}{*}{ Itajubá } & Incubadora de Empresas de Base Tecnológica de Itajubá - INCIT & Residentes & 8 \\
\cline { 2 - 4 } & Associação Comercial, Industrial e Empresarial de Itajubá - ACIEI. & Associadas & 7 \\
\hline
\end{tabular}

Fonte: Dados da pesquisa.

Após o levantamento preliminar dos dados, constatou-se que, das 30 empresas selecionadas, duas foram vendidas para empresas de outro estado; duas se fundiram com outras duas empresas pertencentes à amostra; uma empresa optou por não responder à pesquisa e, para outras quatro, não foi possível conseguir agendamento. A amostra final entrevistada no período de 19/12/2014 a 24/03/2015 foi composta por 21 empresas que representam em torno de $80 \%$ do total de empresas válidas.

Durante a construção da identidade virtual destas empresas, que são de base tecnológica, foram percebidos alguns contrapontos relacionados ao uso das TICs, tais como: inexistência de site empresarial; site fora do ar sem informações aos internautas sobre o motivo de inatividade; divergências entre dados de contato com as empresas, divulgados nos sites empresariais, em comparação com aqueles divulgados nos sites das respectivas incubadoras; tempo de retorno dos contatos por e-mail (usado como recurso principal de comunicação externa por todas as empresas).

Durante a fase de agendamento das entrevistas, novos contrapontos foram observados, como: falta de retorno em contatos realizados através dos canais das empresas nas mídias sociais; número médio de contatos telefônicos por empresa para efetivação dos agendamentos, sendo de cinco na cidade de Santa Rita do Sapucaí, e de dois na cidade de Itajubá. Ao término desta fase o ambiente empresarial Itajubense foi considerado como o mais acolhedor à pesquisa científica. Um panorama geral das empresas selecionadas é apresentado na Tabela 2.

Tabela 2 - Caracterização das empresas entrevistadas

\begin{tabular}{|c|c|c|c|c|c|c|c|c|c|c|}
\hline \multirow{2}{*}{ Cidade } & \multicolumn{2}{|c|}{ Tipo de empresa } & \multicolumn{3}{|c|}{ CNAEs } & \multicolumn{2}{|c|}{ Situação } & \multirow{2}{*}{ T.M.A ${ }^{7}$} & \multirow{2}{*}{ M.P.O ${ }^{8}$} & \multirow{2}{*}{ I.M.E. ${ }^{9}$} \\
\hline & MPES $^{1}$ & $\mathbf{E P P}^{2}$ & A.E.P. ${ }^{3}$ & A.E.S. ${ }^{4}$ & Ambas & Res. $^{5}$ & Grad. ${ }^{6}$ & & & \\
\hline Itajubá & 10 & 00 & 02 & 05 & 03 & 4 & 6 & 4 anos & 8 & 35 anos \\
\hline $\begin{array}{c}\text { Sta. Rita do } \\
\text { Sapucaí }\end{array}$ & 09 & 02 & 01 & 07 & 03 & 5 & 6 & 5 anos & 6 & 33 anos \\
\hline
\end{tabular}

Fonte: Dados da pesquisa.

Legenda:

${ }^{1}$ Micro e Pequenas Empresas

${ }^{2}$ Empresa de Pequeno Porte

${ }^{3}$ Atividade Econômica Principal

${ }^{4}$ Atividade Econômica Secundária

${ }^{5}$ Residente

${ }^{6}$ Graduada

7 Tempo Médio de Atuação

${ }^{8}$ Média de Pessoal Ocupado

${ }^{9}$ Idade média dos empresários 
A pesquisa de campo foi precedida por uma análise da identidade virtual das empresas selecionadas (pesquisa dos sites das empresas e dos perfis existentes nas mídias sociais) como objetivo de verificar, de forma imparcial, as práticas empresariais adotadas no ambiente virtual. Em seguida, foram realizadas as entrevistas, previamente agendadas, para aplicação dos questionários. No início de cada entrevista, os entrevistados foram informados que cada questão deveria ser respondida levando-se em consideração a utilização das mídias sociais (Facebook, Twitter, LinkedIn, Skype, Youtube e WhatsApp) para a realização de todas as atividades. Considerou-se, ainda, a utilização de portais próprios da instituição, sistemas terceirizados, sistemas próprios ou ferramentas de trabalho colaborativo, que oferecessem recursos equivalentes às funcionalidades de uma mídia social, ou que permitissem ligação direta com alguma(s) dela(s). Observações in loco também foram realizadas por sugestões espontâneas dos empresários durante as entrevistas para maior detalhamento das práticas adotadas.

Os dados colhidos durante as entrevistas foram tabulados para análise dos resultados que serão apresentados nas três subseções seguintes, sendo: a) caracterização das empresas; b) premissas para imersão: planejamento, capacitação, motivos para adoção, objetivos da empresa nas mídias sociais e métricas de monitoramento; c) o contexto das imersões: mídias sociais selecionadas e critérios de escolha.

\section{Resultados e discussão}

\subsection{Caracterização das empresas}

A cidade de Itajubá abriga 10 microempresas da amostra, atuantes por um período médio de quatro anos, sendo seis delas empresas graduadas pela Incubadora de Empresas de Base Tecnológica de Itajubá (INCIT) da Universidade Federal de Itajubá (UNIFEI) e quatro ainda em estágio de incubação pela mesma incubadora. Três empresas se encontravam entre os dois primeiros anos de atuação, portanto, na fase mais crítica de sua própria consolidação, no entanto são participativas em evento nacionais de empreendedorismo e inovação e disseminadoras da cultura empreendedora na região. Uma delas motivou a formalização da Rede de Tecnologia da Informação e Comunicação (RETIC), gestora do Arranjo Produtivo Local de Tecnologia da Informação e Comunicação (APLTIC) de Itajubá, arranjo com grandes perspectivas de transformação econômica e social pelas características do setor de TIC. O grau de escolaridade dos empresários entrevistados varia entre a graduação e o mestrado, sendo oito graduados, um especialista e um mestre. A idade média destes empresários é de 35 anos, variando no intervalo de 25 a 53 anos. As empresas ocupam em média oito pessoas, entre sócios, funcionários e estagiários. Duas destas, não possuem funcionários empregados. O número médio de sócios por empresa é de três.

A cidade de Santa Rita do Sapucaí abriga duas empresas de pequeno porte e nove microempresas da amostra, atuantes por um 
período médio de cinco anos, sendo três empresas graduadas pelo Programa Municipal de Incubação Avançada de Empresas de Base Tecnológica - PROINTEC da Incubadora Municipal de Empresas "Sinhá Moreira (IME); três graduadas e duas residentes pelo Núcleo de Empreendedorismo do Instituto Nacional de Telecomunicações INATEL/NEMP; uma graduada e duas residentes pela Incubadora de Empresas de Base Tecnológica do Centro de Ensino Superior em Gestão, Tecnologia e Educação - INTEF/FAI. Quatro empresas se encontravam entre os dois primeiros anos de atuação, portanto, na fase mais crítica de sua própria consolidação, no entanto há jovens empresários premiados em competições nacionais e internacionais de gestão e estratégia. O grau de escolaridade dos empresários entrevistados varia entre a graduação e o mestrado, sendo seis graduados, quatro especialistas e um mestre. A idade média destes empresários é de 33 anos, variando no intervalo de 21 a 50 anos. As empresas ocupam em média seis pessoas, entre sócios, funcionários e estagiários. Três destas não possuem funcionários. 0 número médio de sócios por empresa é três.

Ao considerar-se que: a) grande parte dos empresários, em ambas as cidades, são ex-alunos provenientes das instituições locais de ensino superior, constituindo-se em capital humano diferenciado e b) as empresas estão imersas em incubadoras e/ou fazem parte dos Arranjos Produtivos Locais, o que favorece a interação empresarial em redes de informação e colaboração, além da interação com órgãos governamentais de apoio às MPEs, ao desenvolvimento de uma cultura empreendedora e à prática da inovação, é possível afirmar que, na amostra estudada, há toda uma base propícia para que os empresários sejam classificados como empreendedores por oportunidade (DEGEN, 2008).

\subsection{Premissas para imersão}

\subsubsection{Planejamento e capacitação}

A partir dos dados coletados, foi possível constatar que todas as empresas possuem conhecimentos sobre os recursos pesquisados, sendo que $90 \%$ os adotam em seus trâmites de trabalho. Duas empresas demonstraram não possuir habilidades práticas para uso das mídias embora o assunto não seja desconhecido para ambas. Uma delas é iniciante e sem público alvo definido. Uma terceira empresa declarou não perceber claramente o potencial de uso das mídias, porém sabe que o bom uso depende do foco e da rapidez em responder seus clientes.

As empresas que informaram não utilizar as mídias sociais em seus trâmites de trabalho apresentaram as seguintes justificativas: a) se encontram em início das atividades e não apresentam escala para atender a novos clientes provenientes das mídias sociais; b) não consideram os recursos aplicáveis ao negócio da empresa e alegam dificuldade para monitorar e mensurar os benefícios advindos do uso; c) falta de tempo, pessoas e/ou conhecimento para gerenciá-los. 
Das empresas que afirmaram utilizar os recursos, apenas $26 \%$ alegaram ter realizado planejamento para adoção e somente $21 \%$ tiveram capacitação sobre os mesmos. Apenas um empresário realizou planejamento da implantação e uso das mídias com conhecimento prévio dos riscos e benefícios da adoção, tendo recebido capacitação do Sebrae. Os demais empresários que realizaram planejamento o fizeram tanto pela necessidade de estruturação interna da área produtiva, onde os recursos seriam utilizados como ferramentas de desenvolvimento colaborativo, quanto por experiência prévia de uso fora dos negócios atuais. Este baixo índice de planejamento para adoção e utilização dos recursos indica em duas instâncias que: a) o potencial organizacional dos recursos pesquisados não é claramente percebido/compreendido pelos empresários e b) em consequência, a adoção se dá quase que "por obrigação" ao acompanhamento das tendências tecnológicas atuais, com a perspectiva de "observar" os resultados para decisão posterior de se manter ou não os recursos. Vale ressaltar que, nas áreas produtivas, a experiência anterior de líderes de projeto em ferramentas implantadas justifica a ausência de planejamento, no entanto, o maior número de capacitações se dá exatamente nestas áreas em virtude da necessidade estratégica de transmissão do conhecimento aos demais colaboradores de maneira a garantir a produtividade. Há empresários que relataram perceber a necessidade do planejamento após a utilização dos recursos, quando, por exemplo, criam perfis específicos nas mídias sociais, para cada ferramenta que desenvolvem e, a partir daí, começam a perceber a necessidade de criação de postagens específicas e periódicas para cada público alvo, a necessidade de monitoramento das mídias e de planejamento do tempo para atender às demandas oriundas da utilização, etc. Há percepções de que o uso indevido dos recursos pode comprometer a imagem da empresa.

\subsubsection{Motivos para adoção}

Em relação aos motivos para adoção de mídias sociais nas empresas, observa-se que a maioria dos respondentes (58\%) apontou que a motivação se deu pela necessidade de acompanhamento de tendências, especialmente em relação à utilização destes recursos como canais de divulgação da marca e dos produtos, e de aproximação e relacionamento com os clientes. Seria esperado que a "observância de casos de sucesso" fosse a mais apontada em função da pressão por seguir modelos bem sucedidos para evitar incertezas do mercado; ao contrário, foi uma razão indicada por somente $26 \%$ dos respondentes. No mesmo sentido, a obtenção de $21 \%$ das respostas assinalando a opção "utilização antecipada pelos concorrentes" também pode apontar para um baixo monitoramento das ações dos concorrentes. O segundo maior motivo de adoção das mídias, (42\% das respostas) relaciona-se à adoção por estratégia de inovação, compreendendo por um lado, a possibilidade de percepção de demandas por novos produtos e de novos nichos de mercado e, por outro, a possibilidade de otimização de processos 
internos; e, em seguida, aparecem as escolhas por oportunidade de atualização profissional e outros motivos ( $32 \%$ das respostas). Outros motivos que não constavam no questionário foram apresentados pelos entrevistados, sendo estes: fortalecimento da marca, vendas, praticidade $x$ custo $x$ benefícios, produtos desenvolvidos para uso direto em mídias sociais, integração com ferramentas desenvolvidas na empresa, e como base de conhecimentos, considerando as ferramentas sociais colaborativas.

Desta forma, pode-se inferir pelas respostas que a predisposição das empresas estudadas é de acompanhar as novidades tecnológicas bem como as tendências de sua aplicação aos negócios de forma geral, em detrimento de estudos e planejamentos efetivos para adoção em seu âmbito específico. Tais práticas arriscadas podem resultar em desperdício ou subutilização de recursos em função da falta de alinhamento aos negócios ou estratégias da empresa e ainda pela falta de habilidades para sua gestão. Os resultados encontrados estão apresentados na Figura 2.

Figura 2 - Motivos de adoção das mídias sociais pelas empresas

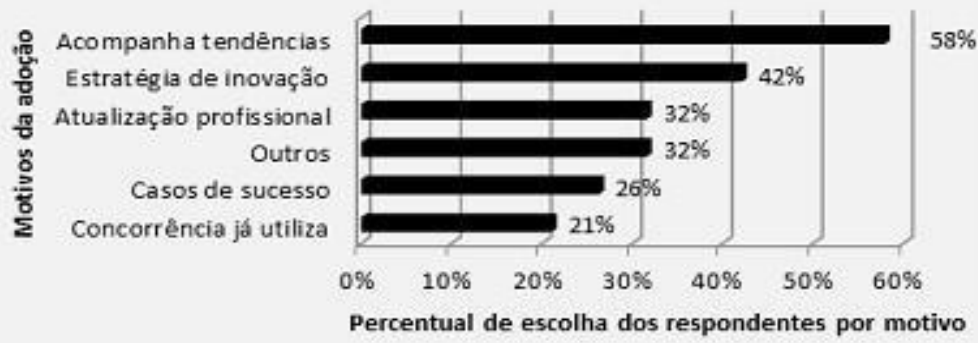

Fonte: Elaborado pelas autoras.

\subsubsection{Objetivos das empresas nas mídias sociais}

Em relação aos objetivos das empresas nas mídias sociais (Figura 3), os resultados apontaram, por ordem de importância: a) aumentar a reputação da marca, com 79\% das respostas; b) aumentar as vendas, com 74\% das respostas; c) melhorar relacionamento com parceiros e potencializar o sucesso de novos produtos, empatados com $63 \%$ das respostas; d) melhorar a qualidade de suporte ao cliente, com 58\% das respostas; e) gerar marketing boca-a-boca, criar vantagem competitiva e inovar o modelo de negócios, empatados com 53\% das respostas; f) aumentar fidelidade do cliente com $47 \%$ das respostas e g) trazer ideias de fora, com $11 \%$ das respostas.

Tais resultados evidenciam a preocupação das empresas com a imagem veiculada nas mídias sociais, fato comprovado até pelo relato daquelas que mantém um perfil de baixa atividade nas mídias, pois acreditam que basta a presença nas mídias para agregar valor à marca. Constata-se, portanto, que estas empresas permanecem no patamar inicial de uso destes recursos, i.e, para fins de marketing e divulgação somente, sem compreenderem que o maior valor advindo da imersão em mídias sociais reside na possibilidade de desenvolvimento do capital 
relacional, ou seja, da capacidade de se estabelecer relações interorganizacionais em múltiplas redes, ligadas por fluxos informacionais diversos (no ciberespaço) que permitam às empresas pioneiras nesta adoção, apreenderem rapidamente (no espaço dos fluxos) novas ideias e perceberem cenários emergentes, bem como novas práticas organizacionais necessárias ao alcance e manutenção de posições competitivas nos mercados (conhecidos ou alcançados), tanto locais, regionais e/ou globais (espaço dos lugares). Neste aspecto, embora os resultados evidenciem uma preocupação em se melhorar o relacionamento com parceiros, durante a observância das práticas de relacionamento com clientes, nota-se que a visão de clientes como parceiros e da formalização de parcerias como oportunidades para a prática de inovações (trazer ideias de fora) não ocorrem nos processos de imersão destas empresas.

Figura 3 - Objetivos das empresas nas mídias sociais

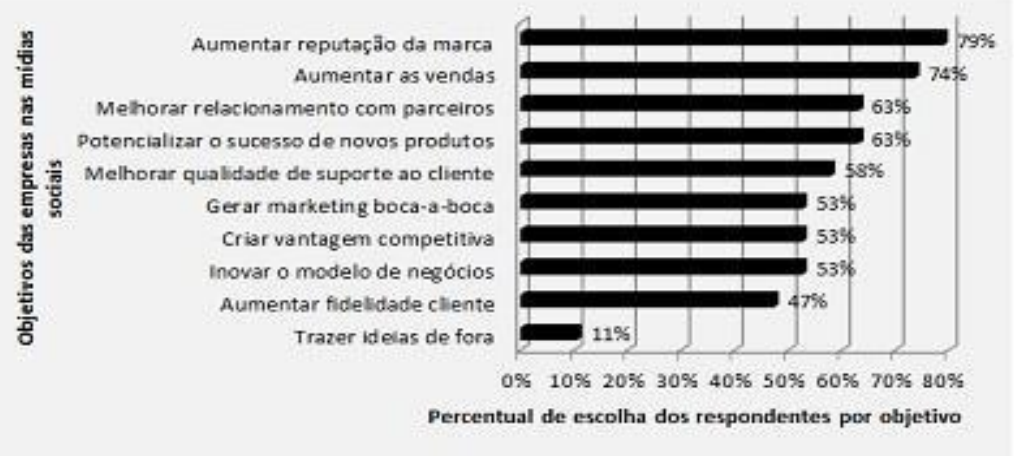

Fonte: Elaborado pelas autoras.

\subsubsection{Métricas de monitoramento}

As métricas mais populares, elencadas para seleção nesta pesquisa, foram: Alcance (47\%), Engajamento (37\%), Tendências (26\%), Taxa de retorno $(21 \%)$, Timing (16\%), Influência (16\%), e Sentimento (16\%). Caso a empresa não as utilizasse, deveria informar os motivos, por ordem de importância, tendo sido elencados os seguintes: a) Custo elevado, b) Falta de tempo, c) Desconhecimento de tecnologias e métricas para este fim, d) Inexistência de pessoa capacitada para tal, e) Inexistência de estratégias da empresa para este fim. A Figura 4 ilustra os resultados encontrados.

Figura 4 - Métricas de monitoramento utilizadas 




Fonte: Elaborado pelas autoras.

Tanto os números quanto os resultados práticos demonstraram baixa atividade no entorno das métricas de monitoramento, em grande parte pelo desconhecimento de ferramentas e recursos das mídias sociais para esse fim e da não existência de estratégias para a realização desta prática, o que se justifica pelo baixo nível de planejamento e capacitação para adoção das mídias, conforme apresentado em resultados anteriores. A maioria dos empresários conseguiu responder à questão após ouvir as explicações dos objetivos de cada métrica e das ferramentas mais comuns utilizadas para este fim. Em duas empresas, foi possível detectar estratégias próprias de monitoramento das métricas de timing, engajamento e alcance, seja pela observação meticulosa da movimentação em torno das postagens em três turnos até se descobrir qual o melhor horário para publicação em cada mídia; seja pela utilização de ferramentas que automatizam e otimizam o processo previamente descrito; seja pela criação de promoções vinculadas a critérios de pontuação baseados em número de compartilhamentos, total de curtidas, etc. ou ainda, em situação mais avançada, pela criação de ferramentas próprias de monitoramento de acessos aos sites empresariais que, ao indicar as páginas e áreas mais acessadas pelos clientes permite aos gerentes de projeto criticarem possíveis melhorias a serem realizadas para garantir acessibilidade ou maior agilidade no acesso.

No universo de 19 empresas, apenas três conhecem o Google Analyticse Google AdWords, porém seus resultados são efetivamente utilizados apenas por duas.

As empresas que afirmaram não utilizar métricas de monitoramento totalizam $47 \%$ da amostra. O principal motivo da não utilização de métricas foi o fato de não existir na empresa pessoa capacitada para realizar a tarefa. Em seguida, outros motivos foram apresentados como justificativas, tais como, desenvolvimento de aplicações próprias para monitoramento, percepção de que tal prática não se aplica ao negócio da empresa, percepção de que tal prática não é necessária para a empresa em função das mídias não serem utilizadas para fins de marketing e divulgação, o aguardo do lançamento de um produto para início de utilização efetiva, utilização de métricas específicas para área produtiva não coincidentes com as demais relacionadas. Por fim, o custo elevado, a 
falta de tempo e o desconhecimento de tecnologias e métricas para este fim inibem a utilização na visão dos empresários.

A consequência mais evidente da falta de capacitação e planejamento para adoção das mídias sociais nas empresas pesquisadas reside nos baixos resultados obtidos quanto à adoção de métricas de monitoramento. Por não conhecerem em profundidade a potencialidade e função das mídias sociais, a compreensão do valor de uma métrica de monitoramento também não é clara para as empresas. Por consequência, a baixa utilização de métricas de monitoramento resultou em baixa percepção dos empresários quanto ao grau de impacto do uso das mídias sociais no desempenho das empresas, já que este resultado depende diretamente de monitoramento planejado e eficiente sobre o uso das mídias sociais visando concluir de forma assertiva seus benefícios ou insucessos.

Em três empresas que utilizam métricas de monitoramento foi possível verificar resultados positivos no desempenho empresarial nos seguintes aspectos: redução do valor do investimento em marketing; aumento do contato com potenciais clientes $\mathrm{e}$, consequentemente 0 aumento do total de clientes ativos; aumento das horas gastas em treinamento em função da redução do custo de capacitações realizadas virtualmente; e aumento do faturamento bruto real, do lucro líquido, do faturamento por novos produtos e do total de ativos destas empresas. Outra observação importante é a de que, mesmo sem adoção sistematizada de métricas, algumas empresas conseguem avaliar o alcance, engajamento e timing relatando grande "prazer" em perceber os impactos provenientes de suas postagens nos canais sociais.

\subsection{0 contexto das imersões}

\subsubsection{Mídias sociais utilizadas}

Para a realização desta pesquisa as mídias sociais foram organizadas em dois grupos, a saber: Ferramentas Sociais de Colaboração e Redes Sociais. O primeiro grupo compreende os Blogs e Microblogs, sendo o Twitter o mais conhecido; Ferramentas de Wiki; Ferramentas de Fórum; Ferramentas para compartilhamento de imagens (Pictures), como o Pinterest; e Ferramentas para compartilhamento de áudio e vídeo, como - Youtube. Durante a pesquisa a campo, foi possível detectar um conjunto específico de ferramentas que, por possuírem características similares às das mídias sociais, além de suas especificidades, foram incluídas neste primeiro grupo. São ferramentas que permitem a organização de redes sociais organizacionais para desenvolvimento de aplicações de forma colaborativa, interações sociais intensas entre os stakeholders, edição colaborativa de artefatos, reuniões virtuais, escritórios virtuais, organização de grupos de trabalho colaborativo virtual, entre outras funções. Assim, as ferramentas Ammyy, Asana, BitBucket, Cacoo, GitHub, HipChat, Hangout, Jira, Podio, RedMine, Sharepoint, TeamViewer, Trello, 
Yammer e Webex passaram a compor a categoria Ferramentas sociais empresariais ${ }^{2}$.

Entre as Ferramentas Sociais de Colaboração, as de compartilhamento de áudio e vídeo são utilizadas por $63 \%$ das empresas participantes, o destaque nesta categoria é para o Youtube. Em seguida estão as Ferramentas de Gestão de Projetos e Colaboração que são utilizadas por $58 \%$ das empresas participantes. As Ferramentas de Blogs e Microblogs são utilizadas por $53 \%$ das empresas participantes, o destaque nesta categoria é para o Twitter, mas há blogs próprios também em uso. Os Wikis e Fóruns são utilizados por $21 \%$ das empresas, nesta categoria há presença de wikis e fóruns próprios. A ferramenta menos utilizada pelas empresas é o Pinterest (Pictures), com apenas 5\% de adoção. 0 destaque para as ferramentas Youtube e Twitter indica que as empresas preferem realizar imersão em mídias mais populares, seja pela facilidade de uso, quanto pela grande possibilidade de obter suporte técnico junto aos stakeholders ali imersos ou na própria internet. Em contrapartida, a mídia apontada como menos utilizada, o Pinterest, permite às empresas, por exemplo, conhecer os interesses de seus stakeholders e criar estratégias específicas para alcançar públicos e mercados ainda não explorados. As mídias sociais em uso pelas empresas ainda não se encontram organizadas em ecossistemas sistematicamente planejados e disseminados entre os stakeholders. A Figura 5 ilustra os resultados encontrados.

Figura 5 - Ferramentas sociais de colaboração utilizadas pelas empresas

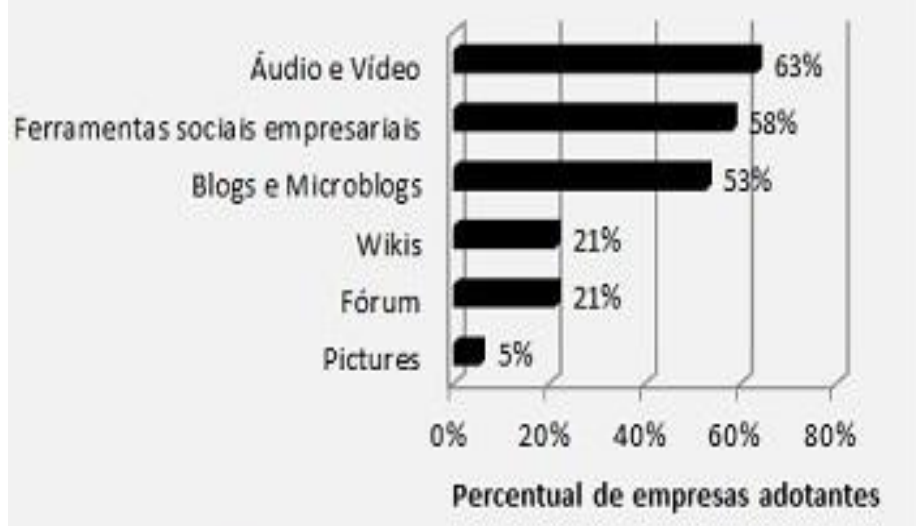

Fonte: Elaborado pelas autoras.

O segundo grupo (Redes Sociais) engloba Facebook, LinkedIn, Google+, Skype, WhatsApp e redes sociais próprias das empresas. Entre estas, as mais utilizadas, o Facebook é o preferido das empresas, sendo adotado por $90 \%$ delas. Na sequência, aparecem por ordem de adoção: Skype (84\%), WhatsApp (53\%) e LinkedIn (42\%). Entre as menos

\footnotetext{
${ }^{2}$ Esta definição baseia-se no estudo de Barbosa, Sepúlveda e Costa (2009, p. 18) onde consta que, dentre três conjuntos de tecnologias que apoiam a gestão do conhecimento dentro de uma organização, um se destaca por se constituir de ferramentas "direcionadas para o apoio da colaboração entre pessoas", permitindo o desenvolvimento de relações e de trâmites empresariais de forma colaborativa. Os autores citam como exemplo a chamada Web 2.0 e suas aplicações.
} 
utilizadas, estão as ferramentas integradas às redes sociais em $26 \%$ das empresas e o Google+ adotado por $21 \%$ das empresas. Um ponto importante a ressaltar é que, em $5 \%$ das empresas, há o desenvolvimento de redes sociais próprias com recursos de integração às redes sociais pesquisadas, indicando que estas buscam agilizar as publicações de conteúdos e, assim sendo, o fortalecimento da marca. Este resultado denota a perspectiva de que as empresas podem vir a se desenvolver no sentido de se tornarem empresas sociais, uma vez que, integrados os sistemas internos às mídias externas, torna-se necessária a adequação de processos internos de utilização e monitoramento dos recursos a fim de mensurar o custo $x$ benefício da adoção e de adotar práticas coerentes com a realidade empresarial. A Figura 6 ilustra os resultados encontrados.

Figura 6 - Redes Sociais utilizadas pelas empresas

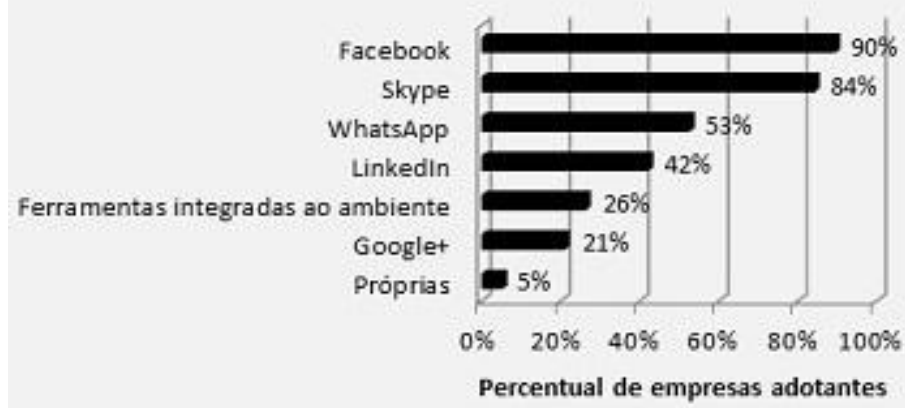

Fonte: Elaborado pelas autoras.

Uma comparação entre os dois grupos de ferramentas analisados acima demonstra que o uso de redes sociais supera o uso das ferramentas sociais de colaboração, o que significa que o maior volume de atividades realizadas pelas empresas na imersão ocorre em nível de interação e colaboração em grupos. E neste aspecto, tais ações agregam benefícios relevantes às empresas, como: percepção de novos nichos de mercado, descoberta de novas fontes de matéria-prima, percepção da demanda de novos produtos, inteligência na execução de práticas estratégicas competitivas e na elaboração de estratégias de engajamento, organização de redes de conhecimento e colaboração entre empresas, governo, instituições financeiras, universidades e setor civil, fortalecimento da marca, reconhecimento da competência dos empresários, percepção de novas aplicações para os produtos desenvolvidos pelas empresas, maior alcance do público-alvo a menor custo (maior diálogo), apoio na melhoria e/ou otimização de processos (há iniciativa de sistematização pela Norma ISO 13485 , de procedimentos de divulgação e vendas considerando-se o uso de mídias sociais em uma empresa), melhoria na qualidade das contratações. Embora a importância destes resultados, eles foram percebidos em apenas quatro empresas da amostra.

De forma geral, observa-se uma utilização variante das mídias sociais por parte das empresas estudadas, partindo-se da baixa à massiva e estrategicamente planejada (em poucos casos). As empresas que 
mantém perfis com baixa atividade alegam que: a) apenas manter o espaço empresarial nas mídias é o suficiente para fortalecer a marca; b) o público alvo é muito tradicional, sem conhecimento e habilidade para uso dos recursos. Rebatendo este argumento, foi descoberta na pesquisa uma empresa que desenvolve soluções móveis para o mesmo nicho de mercado encontrando-se em expansão; c) a empresa passa por momento de reestruturação ou finalização de seu produto principal, por esta razão, - gerenciamento inadequado das mídias poderia contribuir de maneira negativa para a marca da empresa pela falta de tempo para suprir as demandas provenientes destes canais; d) por serem terceirizadas e não possuírem concorrentes para seus produtos, não realizam essas atividades nas mídias. Uma delas possui inclusive identidade bem confusa nas mídias, com denominações diferentes em diversos lugares; e) o foco dos negócios não se direciona para a massificação, sendo então os esforços de divulgação concentrados nos recursos de newsletter, meio pelo qual alegam obter os maiores retornos, sugestões de melhorias e trocas de informações.

\subsubsection{Critérios de escolha}

Os critérios que definem a escolha das mídias sociais pelos empresários são alcance (popularidade/dimensão de público) e recursos oferecidos pelas mídias, conforme $79 \%$ das respostas, em seguida, 0 objetivo da mídia é o critério elencado por $58 \%$ das respostas. Outros motivos foram apontados em $16 \%$ das respostas e compreendem, segundo os empresários: público x custo, demanda de comunicação de parceiros, praticidade $x$ custo $x$ benefício. Tais resultados são coerentes com os resultados alcançados em relação aos objetivos das empresas nas mídias, ou seja, confirma-se que a maior preocupação dos empresários reside na utilização das mídias para promover a marca da empresa (marketing e divulgação) já que o critério de alcance (popularidade) permite, de forma subjetiva, agregar valor a uma marca pelo número de fãs, seguidores, cliques e compartilhamento que seus posts alcançam nas interações em imersão, o que exige perfis dinâmicos, atualizados e monitorados. A atribuição de alta relevância aos recursos oferecidos pelas mídias sociais repousa sobre as características que elas possuem de: a) permitir o compartilhamento de conteúdos digitais em diversos formatos, tais como: áudios, vídeos, documentos, imagens, links de internet, etc., para acesso principalmente por dispositivos móveis, o que aproxima as empresas de seus clientes e parceiros; b) permitir integração com outras mídias sociais, o que simplifica, por exemplo, o processo de publicação e o de acesso; c) permitir o desenvolvimento colaborativo de vários artefatos relacionados a projetos em andamento e reuniões com stakeholders. Tais características puderam ser observadas nos resultados das práticas de imersão das empresas participantes. O critério de objetivo da mídia social se refere à função principal para a qual cada mídia foi criada, como por exemplo, o Twitter, um microblog, o Youtube para compartilhamento de vídeos e o SoundCloud para compartilhamento de músicas, etc. Embora 
este resultado seja relevante, foi possível perceber que, na maioria dos casos a prática de publicação não considera estas particularidades pois os conteúdos são criados para uma mídia principal e linkados nos perfis das empresas nas demais mídias onde realizam imersão.

De forma geral, há evidências de que a percepção do potencial dos recursos para aplicação em outras áreas funcionais além do marketing ainda é pequena, embora o contrário fosse esperado considerando-se as características diferenciais do contexto pesquisado. $O$ baixo grau de capacitação para utilização dos recursos limita sua aplicação e minimiza as possibilidades de utilização criativa dos mesmos com vistas ao fortalecimento empresarial para competição eficiente, já que contribui para a inexistência de estratégias organizacionais e de competências empresariais adequadas à imersão.

A Figura 7 ilustra os resultados encontrados.

Figura 7 - Critérios para escolha das mídias sociais pelas empresas

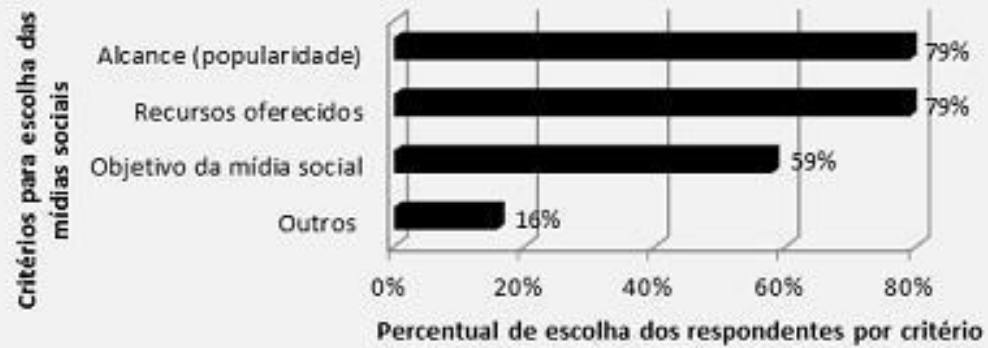

Fonte: Elaborado pelas autoras.

\section{Conclusões}

O objetivo deste artigo foi apresentar as práticas adotadas pelas MPEs desenvolvedoras de software através da utilização de mídias sociais em seus trâmites interorganizacionais. Neste sentido, através da percepção empresarial sobre as oportunidades de exploração do ciberespaço, constatou-se que a importância da imersão não é tão significativa entre as empresas pesquisadas, mesmo estas sendo de base tecnológica. Salvo algumas exceções, as competências necessárias ao melhor aproveitamento operacional e estratégico dos recursos ainda não foram desenvolvidas, o que inviabiliza o alcance das potencialidades esperadas com a imersão, tal como o aumento da competitividade ou a melhoria no desempenho colaborativo. De forma geral, a adoção das mídias sociais não é precedida de capacitação, nem de planejamento, consequentemente, as práticas de imersão não são sistematizadas nem monitoradas, o que dificulta o acompanhamento de seus impactos.

O maior valor atribuído às mídias sociais ainda repousa sobre as atividades de marketing e divulgação, excetuando-se nas empresas que utilizam os CNAES selecionados em sua atividade principal. Estas utilizam as mídias sociais de maneira expressiva na área produtiva irradiando-se progressivamente para outras áreas. 
Desta forma, conclui-se que as empresas pesquisadas não apresentam práticas constantes e consolidadas em seus processos de negócios. Parece haver indícios de um processo gradativo de imersão em áreas estratégicas dentro das empresas, o que sugere uma tendência ao desenvolvimento de know-how para condução de todos os trâmites organizacionais aos ambientes de imersão. Tal proposição é aceitável a partir do momento em que a disseminação de pesquisas e práticas tem se tornado mais frequente nos meios onde essas empresas atuam, o que permite maior visão sobre a necessidade de adaptar a organização aos contextos tecnológicos e econômicos atuais.

\section{Referências}

ABREU, N.R. de; BALDANZA, R. F.; SETTE, R. de S. Comunidades virtuais como ambiente potencializador de estratégias mercadológicas: locus de informações e trocas de experiências vivenciadas. Perspectivas em Ciência da Informação, Belo Horizonte, v.13, n.3, p.116-136, set./dez. 2008.

ALAM, S. S.; NOOR, M. K. M. ICT Adoption in Small and Medium Enterprises: an empirical evidence of service sectors in Malaysia. International Journal of Business and Management, v.4, n. 2, p.112-125, feb. 2009.

ALBERGHINI, E.; CRICELLI, L.; GRIMALDI, M. A methodology to manage and monitor social media inside a company: a case study. Journal of Knowledge Management, v. 18, n. 2, p. 255-277, 2014.

ALMEIDA, H.; BRIONES, A. J.; FERNANDES, S. B. Determinants of entrepreneurship in small and medium enterprises in the defense sector. China-USA Business Review, v. 11, n. 6, p. 796-810, 2011.

ANTLOVÁ, K. Motivation and barriers of ICT adoption in small and medium-sized enterprises. $\&$ \& $M$ Ekonomie a Management, TechnickaUniv\&Liberci, Czech Republic, n. 12, seção 2, p. 140-155, Apr. 2009.

ARORA, A.; ARORA, A. S.; PALVIA, S. Social media index valuation: impact of technological, social, economic, and ethical dimensions. Journal of Promotion Management, v. 20, n. 3, p. 328-344, 2014.

ASHRAFI, R.; MURTAZA, M. Use and impact of ICT on SMEs in Oman. Electronic Journal Information Systems Evaluation, v.11, n. 3, p.125-138, 2008.

ASSOCIAÇÃO PARA PROMOÇÃO DA EXCELÊNCIA DO SOFTWARE BRASILEIRO (SOFTEX).TIC Brasileira. 2013. Disponível em: <http://www.softex.br/ti-brasileira/>. Acesso em: 4 nov. 2013. 
BARBOSA, R. R.; NASSIF, M. E. Práticas de gestão e de tecnologia da informação e seu relacionamento com o desempenho organizacional. Perspectivas em Gestão \& Conhecimento, João Pessoa, v. 2, n. esp., p. 104-117, out. 2012.

BARBOSA, R. R.; SEPÚlVEDA, M. I. M.; COSTA, M. U. Pereira da. Gestão da informação e do conhecimento na era do compartilhamento e da colaboração. Informação e Sociedade: Est., João Pessoa, v.19, n.2, p. 1324, maio/ago. 2009.

BARROS, A. A. de; PEREIRA, C. M. M. de A. Empreendedorismo e crescimento econômico: uma análise empírica. RAC, Curitiba, v.12, n.4, p.975-993, out./dez.2008.

BECK, T. Bank financing for SMEs: lessons from the literature. National Institute Economic Review, n. 225, p. R23-R24, Aug. 2013.

BANCO NACIONAL DE DESENVOLVIMENTO ECONÔMICO E SOCIAL (BNDES). Circular no 11, de 2010. Rio de Janeiro, 2010. Disponível em: <http://www.bndes.gov.br/SiteBNDES/export/sites/default/bndes_pt/Gale rias/Arquivos/produtos/download/Circ011_10.pdf $>$. Acesso em: 5 fev. 2015.

BANCO NACIONAL DE DESENVOLVIMENTO ECONÔMICO E SOCIAL (BNDES). Circular no 34, de 2011. Rio de Janeiro, 2011. Disponível em: <http://www.bndes.gov.br/SiteBNDES/export/sites/default/bndes_pt/Gale rias/Arquivos/produtos/download/Circ034_11.pdf $>$. Acesso em: 5 fev. 2015.

BOHN, N.; KUNDISCH, D. Much more than "same solution using a different technology": antecedents and consequences of technology pivots in software startups. In: MULTIKONFERENZ WIRTSCHAFTSINFORMATIK, 2018, March 6 - 9, 2018, Lüneburg, Germany. Disponível em: <http://mkwi2018.leuphana.de/wp-content/uploads/MKWI 40.pdf>.

Acesso em: 1 maio 2018.

BOLSINGER, K.; STAFF, M. The begginers guide to social media. Disponível em: <http://socialwebmedia.ca/wpcontent/uploads/2015/03/beginners_guide_to_social_media.pdf $>$. Acesso em: 3 nov. 2014.

BONSÓN, E.; FLORES, F. Social media and corporate dialogue: the response of global financial institutions. Online Information Review, v. 35, n. 1, p. 34-49, 2011.

BRADLEY, A. J.; MCDONALD, M. P. Mídias Sociais na organização: como liderar implementando mídias sociais e maximizar os valores de seus clientes e funcionários. São Paulo: M. Books do Brasil, 2013.

BRASIL. Lei no 7.256 de 27 de novembro de 1984. Estabelece normas integrantes do Estatuto da Microempresa, relativas ao tratamento diferenciado, simplificado e favorecido, nos campos administrativo; tributário, previdenciário, trabalhista, creditício e de desenvolvimento 
empresarial. Diário Oficial da República Federativa do Brasil, Brasília, DF, no 229, 28 nov. 1984. Seção I, p. 1-4.

BRASIL. Constituição da República Federativa do Brasil. Brasília, 1988. Disponível

em:

<http://www.senado.gov.br/legislação/const/default.shtm>. Acesso em: 5 nov. 2012.

BRASIL. Lei no 9.841 de 5 de outubro de 1999. Institui o Estatuto da Microempresa e da Empresa de Pequeno Porte, dispondo sobre o tratamento jurídico diferenciado, simplificado e favorecido previsto nos arts. 170 e 179 da Constituição Federal. Diário Oficial da República Federativa do Brasil, Brasília, DF, no 192, 6 out. 1999. Seção I, p. 1-4.

BRASIL. Lei Complementar no 123 de 14 de dezembro de 2006. Institui o Estatuto Nacional da Microempresa e da Empresa de Pequeno Porte; altera dispositivos das Leis no 8.212 e 8.213, ambas de 24 de julho de 1991, da Consolidação das Leis do Trabalho - CLT, aprovada pelo DecretoLei $\mathrm{n}^{\circ} 5.452$, de $1^{\circ}$ de maio de 1943 , da Lei $\mathrm{n}^{\circ} 10.189$, de 14 de fevereiro de 2001, da Lei Complementar no 63, de 11 de janeiro de 1990; e revoga as Leis $\mathrm{n}^{\circ}$ 9.317, de 5 de dezembro de 1996, e 9.841, de 5 de outubro de 1999. Diário Oficial da República Federativa do Brasil, Brasília, DF, no 240, 15 dez. 2006. Seção I, p. 1-10.

BRASIL.. Portal Brasil. Mapa das micro e pequenas empresas. Seção Economia e Emprego. Disponível em: <http://www.brasil.gov.br/economia-e-emprego/2012/02/o-mapa-dasmicro-e-pequenas-empresas >. Acesso em: 5 maio 2014.

BUGHIN, J.; BYERS, A. H.; CHUI, M. How social technologies are extending the organization. McKinsey Quarterly, v. 20, n. 11,p. 1-10, Nov. 2011.

CAIÇARA JUNIOR, C.Sistemas Integrados de Gestão - ERP: uma abordagem gerencial Curitiba: Intersaberes, 2012.[livro eletrônico].

CASTELLS, M. A Sociedade em rede: a era da informação: economia, sociedade e cultura, São Paulo: Paz e Terra, 1999.v. 1.

CAVAZZA, F. Social media landscape 2015. FredCavazza.net. 2015. Disponível em:<http://www.fredcavazza.net/2015/06/03/social-medialandscape-2015/>. Acesso em: 4 ago. 2014.

CHOSHIN, M.; GHAFFARI, A. An investigation of the impact of effective factors on the success of e-commerce in small- and medium-sized companies.Computers in Human Behavior, n.66, p.67-74, 2017.

CONFEDERAÇÃO NACIONAL DO COMÉRCIO (CNC). As micro e pequenas empresas no Brasil. Rio de Janeiro, 2000.

CONFEDERAÇÃO NACIONAL DO COMÉRCIO (CNC). Empresômetro MPE. 2015. Disponível em:<http://empresometro.cnc.org.br/>. Acesso em: 6, jul. 2015. 
CONFEDERAÇÃO NACIONAL DO COMÉRCIO (TVCNC). O papel econômico e social das MPEs. 2015. Disponível em: <https://www.youtube.com/watch?v=w-z18hPrTH0>. Acesso em: 5 jan. 2015.

CRAVO, T. A.; GOURLEY, A.; BECKER, B. SMEs and regional economic growth in Brazil.Small Business Economics, n.38, p. 217-230, Feb. 2012.

CRESSY, R. Why do most Firms Die Young? Small Business Economics, v. 26, n. 2, p.103-116, 2006.

DA SILVEIRA, G.; BORESTEINS, D.; FOGLIATO, F. Mass customization: literature review and research directions. International Journal of Production Economics, n. 72, p. 1-13, 2001.

DAFT, R. L. Organização, teorias e projetos. São Paulo: Cengage, 2015.

DELOITTE TOUCHE TOHMATSU LIMITED (DELLOITE).Mídias sociais nas empresas: o relacionamento online com o mercado. 2010. Disponível em: $<$ http://www.deloitte.com/assets/dcom-

brazil/local\%20assets/documents/estudos $\% 20 \mathrm{e} \% 20$ pesquisas/apresentac ao_midiassociais.pdf >. Acesso em: 8 set. 2014.

DIJKMANS, C.; KERKHOF, P.; BEUKEBOOM, C. J. A stage to engage: social media use and corporate reputation. Tourism Management, v. 47, p. 5867, 2015.

DEGEN, R. J. Empreendedorismo: uma filosofia para o desenvolvimento sustentável e a redução da pobreza. Revista de Ciências da Administração, v.10, n. 21, p.11-30, maio/ago. 2008.

DOER, R. Investigating barriers to SME growth and development in transition environments: a critique and suggestions for developing the methodology. International Small Business Journal, v.27, n.3, p. 275-305. 2009.

FIRE, M.; PUZIS, R.Organization mining using online social networks. Networks and Spatial Economics, v. 16, p. 545-578, 2016.

GARÓFALO, G. de L. As micro e pequenas empresas em um contexto de desenvolvimento econômico: realidade brasileira e confronto com Portugal. In: CONGRESSO INTERNACIONAL DE ECONOMIA APLICADA, 23., 2009, Covilhã. Anales... Madrid (Espanha): Delta Publicaciones, 2009. p. 2806-2819.

GLOBAL ENTREPRENEURSHIP MONITOR (GEM). [Seção Country profiles]. 2015. Disponível em: <http://www.gemconsortium.org/countryprofile/46>. Acesso em: 8 jun. 2015.

HANNA, R.; ROHM, A.;CRITTENDEN, V. L.We're all connected: the power of the social media ecosystem. Business Horizons, n.54, p.265-273. 2011.

HENDERSON, J. C.; VENKATRAMAN, N. Strategic alignment: a model for organizational transformation via information technology .Cambrige: Sloan 
School of Management; Massachusetts Institute of Technology, 1990.(Working Paper, 3223-901).

HOUSSEIN, M. F. et al. Impact of innovation, technology and economic growth on entrepreneurship. American International Journal of Contemporary Research, v. 1, n. 1, p. 45-51, July, 2011.

INTERACTIVE ADVERTISING BUREAU (IAB).Social media ad metrics definition.2011. Disponivel em: <http://www.iab.net/media/file/SocialMediaMetricsDefinitionsFinal.pdf>. Acesso em: 10 nov. 2014.

INTER-AMERICAN DEVELOPMENT BANK (IADB). Entrepreneurship in emerging economies, the creation and development of new firms in Latin America and East Asia:summary report. Washington, DC: IADB, 2002.

INSTITUTO BRASILEIRO DE GEOGRAFIA E ESTATÍSTICA (IBGE). Pesquisa de serviços de tecnologia da informação. Rio de Janeiro: IBGE, 2011.

INSTITUTO BRASILEIRO DE GEOGRAFIA E ESTATÍSTICA (IBGE). Pesquisa industrial de inovação tecnológica (PINTEC). Rio de Janeiro: IBGE, 2013.

JARRACHI, M.; SAWYER, S. Social technologies, informal knowledge practices and the enterprise.Journal of Organizational Computing and Electronic Commerce, v. 23, n. 1, p. 110-137, 2013.

JORDAN EDMISTON GROUP (JEGI). INTERACTIVE ADVERTISING BUREAU (IAB).The social media ecosystem report: rise of users, intelligence and operating systems. New York: The Jordan Edmiston Group, 2012.

KAPLAN, A. M.; HAENLEIN, M. Users of the world, unite! The challenges and opportunities of social media.Business Horizons, v. 53, n. 1, p. 59-68, 2010.

KHAN, N.; AL-YASIRI, A. Framework for cloud computing adoption: a roadmap for smes to cloud migration. International Journal on Cloud Computing: Services and Architecture (IJCCSA), v. 5, n. 5/6, p. 1-15, 2016.

LA ROVERE, R. L. As pequenas e médias empresas na economia do conhecimento. In: LASTRES, H. M.; ALBAGLI, S. (Org.). Informação e globalização na era do conhecimento. Rio de Janeiro: Campus, 1999. p. 145-163.

LAROSILIERE, G. D.; CARTER, L. D.; MESKE, C.How does the world connect?Exploring the global diffusion of social network sites.Journal of the Association for Information Science and Technology, v. 68, n. 8, p. 1875-1885, 2017.

LASTRES, H. M. M. et al. Desafios e oportunidades da era do conhecimento. São Paulo em Perspectiva, v. 16, n. 3, p. 60-66. 2002. Disponível em: http://www.scielo.br/scielo.php?script=sci arttext\&pid=S010288392002000300009. Acesso em: 13 dez. 2018. 
LATOUR, B. Networks, societies, spheres: reflections of an actornetwork theorist. In: INTERNATIONAL SEMINAR ON NETWORK THEORY, Los Angeles, 2010. Network multidimensionality in the digital age.Los Angeles: Annenberg School for Communication and Journalism,2010.Disponível em: <http://www.brunolatour.fr/sites/default/files/121-CASTELLS-GB.pdf>. Acesso em: 12 jan. 2015.

LAUDON, K.; LAUDON, J. Sistemas de informações gerenciais. São Paulo: Pearson Education do Brasil, 2010.

LEENDERS, R. T. A. J.; DOLFSMA, W. A. Social networks for innovation and new product development.Journal of Product Innovation Management, v.33, n.2, p. 123-131, 2016.

LEÓN, G.; GUTIERREZ, H. L. B.; FARRERO, J. M. C. Evaluation of the perception and application of social responsibility practices in micro, small and medium companies in Barranquilla: an analysis from the theory of Stakeholders. Estudios Gerenciales, v. 33, n.144, p.261-270. 2017.

LÉVY, P. O que é o virtual? São Paulo: Editora 34, 1996.

LÉVY, P. Tecnologias da inteligência: o futuro do pensamento na era da informática. Tradução de Carlos Irineu da Costa. São Paulo: Editora 34, 1998.

LÉVY, P. Cyberculture. Minneapolis: University of Minnesota Press,2001.

MARTELETO, R. M. Análise de redes sociais: aplicação nos estudos de transferência da informação. Ciência da Informação, v. 30, n. 1, p. 71-81, jan./abr. 2001.

MATOS, M. P.de; ARROIO, A. Políticas de apoio a micro e pequenas empresas no Brasil: avanços no período recente e perspectivas futuras Comisión Económica para América Latina y el Caribe (CEPAL). Santiago de Chile:Naciones Unidas, 2011.

MATTOS, J. R. L. de; GUIMARÃES, L. dos S. Gestão da tecnologia e inovação: uma abordagem prática. São Paulo: Saraiva, 2005.

MELLO, S. C. B. de; FONSECA, F. R. B.; VIEIRA, R. S. G. Sensemaking e o desenvolvimento de redes de relacionamentos de negócios no contexto das empresas de base tecnológica. O\&S, Salvador, v.19, n.61, p. 253275, abr./jun. 2012.

MONTEIRO, D.; AZARITE, R.Monitoramento e métricas de mídias sociais: do estagiário ao CEO. São Paulo:DVS Editora, 2012.

MORIONES, A. B.; LÓPEZ, F. L. A firm-level analysis of determinants of ICT adoption in Spain. Technovation, n.27, p. 352-366, 2007.

MOZAS-MORAL, A. et al. Factors for success in online social networks: an fsQCA approach. Journal of Business Research, v. 69, n. 11, p. 52615264, 2016. 
NAGLE, T.; POPE, A. Understanding social media business value, a prerequisite for social media selection. Journal of Decision Systems, v. 22, n. 4, p. 283-297, 2013.

NGAI, E. W. T. et al. Social media models, technologies, and applications: an academic review and case study. Industrial Management \& Data Systems, v. 115, n. 5, p.769-802, 2015.

NGUYEN, ThuyUyen H.; NEWBY, Michael; MACAULAY, Michael J. Information Technology Adoption in Small Business: Confirmation of a Proposed Framework. Journal of Small Business Management, v.53, n.1, p.207-227, 2015.

ORGANIZAÇÃO INTERNACIONAL DO TRABALHO (OIT). Seção Notícias. O trabalho é a principal via pela qual os frutos do desenvolvimento podem chegar até as pessoas. Disponível em: <http://www.ilo.org/brasilia/not\%C3\%ADcias/WCMS_336468/lang-pt/index.htm>. Acesso em: abr. 2015.

ORGANIZAÇÃO PARA A COOPERAÇÃO E O DESENVOLVIMENTO ECONÔMICO (OCDE). Manual de Oslo: proposta de diretrizes para coleta e interpretação de dados sobre inovação tecnológica. [S.I.]: FINEP, 2004.

OLIVEIRA, M.; BERTUCCI, M. da G. E. de S. A pequena e a média empresa e a gestão da informação. Informação e Sociedade, João Pessoa, v. 13, n. 2, p. 65-87, jul./dez. 2003.

OLIVEIRA, F. B. de (Org.). Tecnologia da informação e da comunicação: a busca de uma visão ampla e estruturada. São Paulo: Pearson Prentice Hall; Fundação Getúlio Vargas, 2007.

ORGANIZAÇÃO INTERNACIONAL DO TRABALHO (OIT). Women and men in the informal economy: a statistical picture. 3. ed. Geneve:IOT,2018.

PALACIOS-MARQUÉS, D.; MERIGÓ, J. M.; SOTO-ACOSTA, P. Online social networks as an enabler of innovation in organizations. Management Decision, n.9, v.53, p. 1906-1920, 2015.

PASCHEN, J. Choose wisely: crowdfunding through the stages of the startup life cycle. Business Horizons, v. 60, n. 2, p. 179-188, 2017.

PETERS, K. et al. Social media metrics: a framework and guidelines for managing social media. Journal of Interactive Marketing, n.27, p. 281298. 2013.

RADAS, S.; BOZIC, L.The antecedents of SME innovativeness in an emerging transition economy. Technovation, n. 29, p. 438-450, 2009.

RAMADANI, V. et al. Innovation and economic development: the case of FYR of Macedonia. Journal of Balkan and Near Eastern Studies, v. 15, n. 3, p. 324-345. 2013.

RAZMERITA, L.; KIRCHNER, K.; NABETH, T. Social media in organizations: leveraging personal and collective knowledge processes. Journal of 
Organizational Computing and Electronic Commerce, n. 24, p.74-93, 2014.

RECUERO, R. Redes sociais na Internet. Porto Alegre: Sulina, 2009.

REZENDE, A. D. Sistemas de informações organizacionais: guia prático para projetos em cursos de administração, contabilidade e informática. Paraná: Atlas, 2007.

RIVERA, J. M. C. R. An ex-post comparative analysis of SME formation in Brazil and Mexico. International Journal of Emerging Markets, v. 2, n. 2, p. 144-165. 2007.

SANTOS, J. L. dos; SAMPAIO, R. R. Redes sociais informais e difusão do conhecimento: uma proposta de modelagem em um ambiente de desenvolvimento de projetos de software. Perspectivas em Ciência da Informação, Belo Horizonte, v.21, n.3, p.134-164, jul./set. 2016.

SERVIÇO BRASILEIRO DE APOIO À MICRO E PEQUENA EMPRESA (SEBRAE). Lei Geral das micro e pequenas empresas. São Paulo, 2012. Disponível em: <http://www.sebraesp.com.br/index.php/component/content/article/166produtos-online/legislacao/publicacoes/artigos/6832-pelga/>. Acesso em: 2 fev. 2015.

SERVIÇO BRASILEIRO DE APOIO À MICRO E PEQUENA EMPRESA (SEBRAE) Anuário do trabalho na micro e pequena empresa. São Paulo, 2013. Disponível em: <http://gestaoportal.sebrae.com.br/customizado/estudos-epesquisas/anuario-do-trabalho-na-mpe/anuario-do-trabalho-na-micro-epequena.pdf >. Acesso em: 7 abr. 2014.

SERVIÇO BRASILEIRO DE APOIO À MICRO E PEQUENA EMPRESA (SEBRAE). Quem são os pequenos negócios? Brasília, 2015a. Disponível em:

<http://www.sebrae.com.br/sites/PortalSebrae/estudos_pesquisas/Quems\%C3\%A3o-os-pequenos-neg\%C3\%B3cios\%3F, destaque,5>. Acesso em: 2 fev. 2015.

SERVIÇO BRASILEIRO DE APOIO À MICRO E PEQUENA EMPRESA (SEBRAE). Leis. Santa Catarina, 2015b. Disponível em: <http://www.sebrae-sc.com.br/leis/default.asp?vcdtexto $=4154>$. Acesso em: fev. 2015.

SCHUMPETER, J. A. Teoria do desenvolvimento econômico: uma investigação sobre lucros, capital, crédito, juro e o ciclo econômico. Tradução de Maria Sílvia Possas. São Paulo:Editora Nova Cultural, 1997.

SINGARAJU, S. P. et al. Social media and value co-creation in multistakeholder systems: a resource integration approach. Industrial Marketing Management, [S.I.], v. 54, p.44-55, 2016. 
SOARES, S. A.; BORGES, A. A mídia e suas perspectivas no contexto da propaganda e da comunicação mercadológica. E-COM, Belo Horizonte, v.2, n.2, p. 1-18, nov 2008.

SOUZA, J. H.; MACHADO, L. C.; OLIVEIRA, C. A. S. As origens da pequena empresa na Brasil. Revista da Micro e Pequena Empresa, Campo Limpo Paulista, v.1, n.1, p.53-65, 2007.

STOJANOVA, T.; SUZIC, N.; ORCIK, A. Implementation of mass customization tools in small and medium enterprises. International Journal of Industrial Engineering and Management, v. 3, n. 4, p. 253-260. 2012.

SVENSSON, C.; BARFORD, A. Limits and opportunities in mass customization for "build to order" SMEs. Computers in Industry, v. 49, $\mathrm{n}$. 1, p. 77-89, 2002.

TAMBUNAN, T. SME development, economic growth, and government intervention in a developing country: the Indonesian story. Journal of International Entrepreneurship, n. 6, p. 147-167, 2008.

TARUTÊ, A.; GATAUTIS, R. ICT impacts on SMEs performance.Procedia Social and Behavioral Sciences, n. 110, p. 1218-1225, 2014.

TIGRE, P. B. Gestão da inovação: a economia da tecnologia no Brasil. Rio de Janeiro: Elsevier, 2011.

TOMLINSON, P. R.; FAI, F. M. The nature of SME co-operation and innovation: a multi-scalar and multi-dimensional analysis. Int. J. Production Economics, n. 141, p. 316-326, 2013.

VALE, G. M. V.; GUIMARÃES, L. de O. Redes sociais, informação, criação e sobrevivência de empresas. Perspectivas em Ciência da Informação, v.15, n.3, p.195-215, set./dez 2010.

WEGNER, D.; MISOCSKY, M. C. Avaliação de desempenho de redes de Pequenas empresas: contribuições da Abordagem da produção de sentido. O\&S ,Salvador, v.17, n.53, p. 345-361, abr./jun. 2010.

ZUPPO, C. M. Defining ICT in a boundaryless world: the development of a working hierarchy. International Journal of Managing Information Technology (IJMIT), v.4, n.3, p. 13-22, Aug. 2012. 